\title{
Overview of pool hydraulic design of Indian prototype fast breeder reactor
}

\author{
K VELUSAMY, P CHELLAPANDI, S C CHETAL and BALDEV RAJ \\ Indira Gandhi Centre for Atomic Research, Kalpakkam 603102 \\ e-mail: kvelu@igcar.gov.in
}

MS received 18 February 2008; revised 19 January 2010; accepted 21 January 2010

\begin{abstract}
Thermal hydraulics plays an important role in the design of liquid metal cooled fast breeder reactor components, where thermal loads are dominant. Detailed thermal hydraulic investigations of reactor components considering multi-physics heat transfer are essential for choosing optimum designs among the various possibilities. Pool hydraulics is multi-dimensional in nature and simple one-dimensional treatment for the same is often inadequate. Computational Fluid Dynamics (CFD) plays a critical role in the design of pool type reactors and becomes an increasingly popular tool, thanks to the advancements in computing technology. In this paper, thermal hydraulic characteristics of a fast breeder reactor, design limits and challenging thermal hydraulic investigations carried out towards successful design of Indian Prototype Fast Breeder Reactor (PFBR) that is under construction, are highlighted. Special attention is paid to phenomena like thermal stratification, thermal stripping, gas entrainment, inter-wrapper flow in decay heat removal and multiphysics cellular convection. The issues in these phenomena and the design solutions to address them satisfactorily are elaborated. Experiments performed for special phenomena, which are not amenable for CFD treatment and experiments carried out for validation of the computer codes have also been described.
\end{abstract}

Keywords. Fast reactor; sodium; computational fluid dynamics; multi-physics heat transfer; code validation; experiments.

\section{Introduction}

Indian nuclear power programme has been envisaged to have three stages for judicious utilization of limited uranium and vast thorium resources. In the first stage, Pressurised Heavy Water Reactors are deployed which use natural uranium as fuel and generate plutonium as a by-product, which is fissile. Utilisation of uranium in this type of reactors is very less. In order to utilize the rest of uranium, the second stage is envisaged. In the second stage, fast breeders are deployed. The core of a fast breeder is surrounded by natural or depleted uranium as blanket material, which in due course gets converted to plutonium. The plutonium thus generated in a fast breeder is more than that is used for fission, leading to breeding ratio $>1$. The third stage reactors are also breeders working on thorium-uranium cycle. 


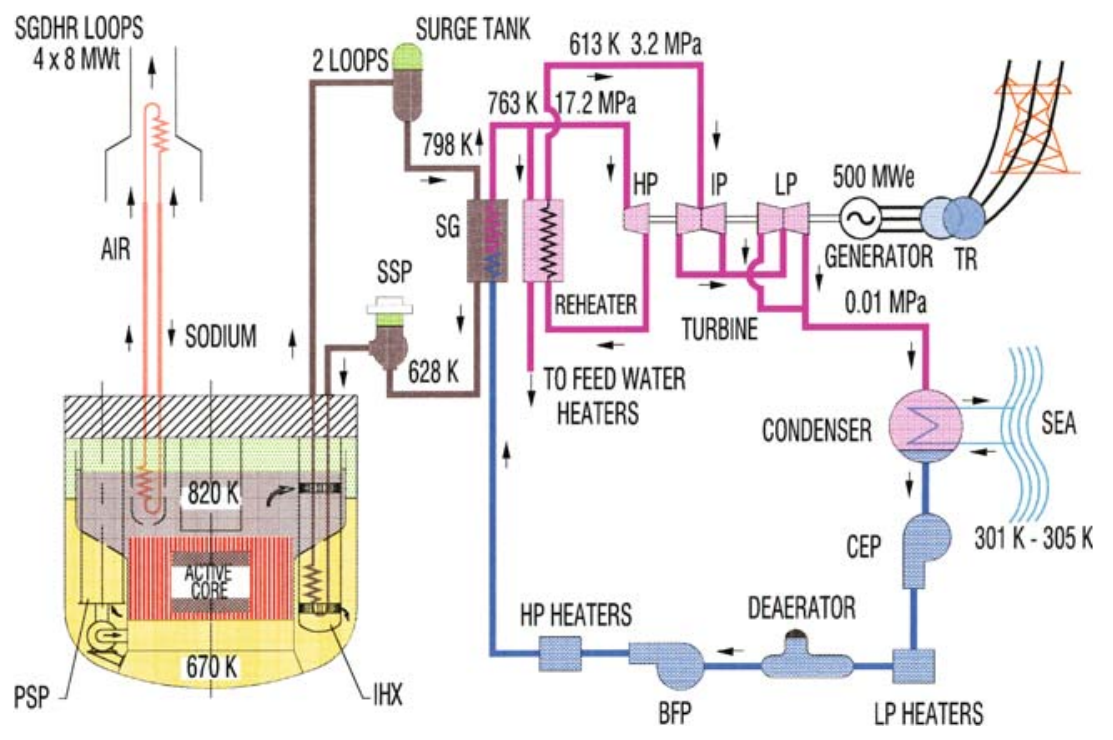

Figure 1. Flow sheet of prototype fast breeder reactor.

Indira Gandhi Centre for Atomic Research is responsible for developing fast breeder reactor technology for India. A loop type Fast Breeder Test Reactor (FBTR) of $40 \mathrm{MW}$ thermal power is under operation at this centre. Towards technical demonstration of large-size fast reactors, a 500 MWe pool type Prototype Fast Breeder Reactor (PFBR) is under construction at Kalpakkam. Pool type reactors have a large volume of primary sodium with its associated thermal capacity that favourably attenuates thermal transients in the primary structures. Moreover, the main vessel that houses radioactive primary sodium is free of any penetrations/pipe connections, which is desirable from structural integrity considerations of the vessel. Flow sheet of PFBR (figure 1) depicts the radioactive primary sodium system, non-radioactive secondary sodium system and conventional steam-water system (Chetal et al 1995). This paper is focussed towards providing an overview of pool hydraulic design of the primary sodium system.

Figure 2 depicts reactor assembly of PFBR, wherein the entire primary circuit consisting of reactor core, control plug, intermediate heat exchangers (IHX), decay heat exchangers (DHX), primary sodium pumps (PSP), grid plate and core support structure are immersed in a pool of liquid sodium (1200 t). The grid plate is a high-pressure plenum, which feeds cold primary sodium to various sub-assemblies that constitute core. The core sub-assemblies and grid plate are supported by core support structure, which rests on main vessel. Primary sodium pool is divided into hot pool and cold pool by a thin structure known as inner vessel. The IHX and PSP penetrate inner vessel.

Design of a fast breeder reactor demands detailed knowledge of thermal hydraulic parameters prevailing in the reactor at various conditions, prediction of which poses interesting challenges. Towards achieving a sound thermal hydraulic design of PFBR, both theoretical and experimental approaches have been followed at this centre. The present paper focuses on thermal hydraulic characteristics of fast breeders, temperature limits to be considered, innovative thermal hydraulic analysis methods developed for understanding special phenomena and design solutions adopted. 


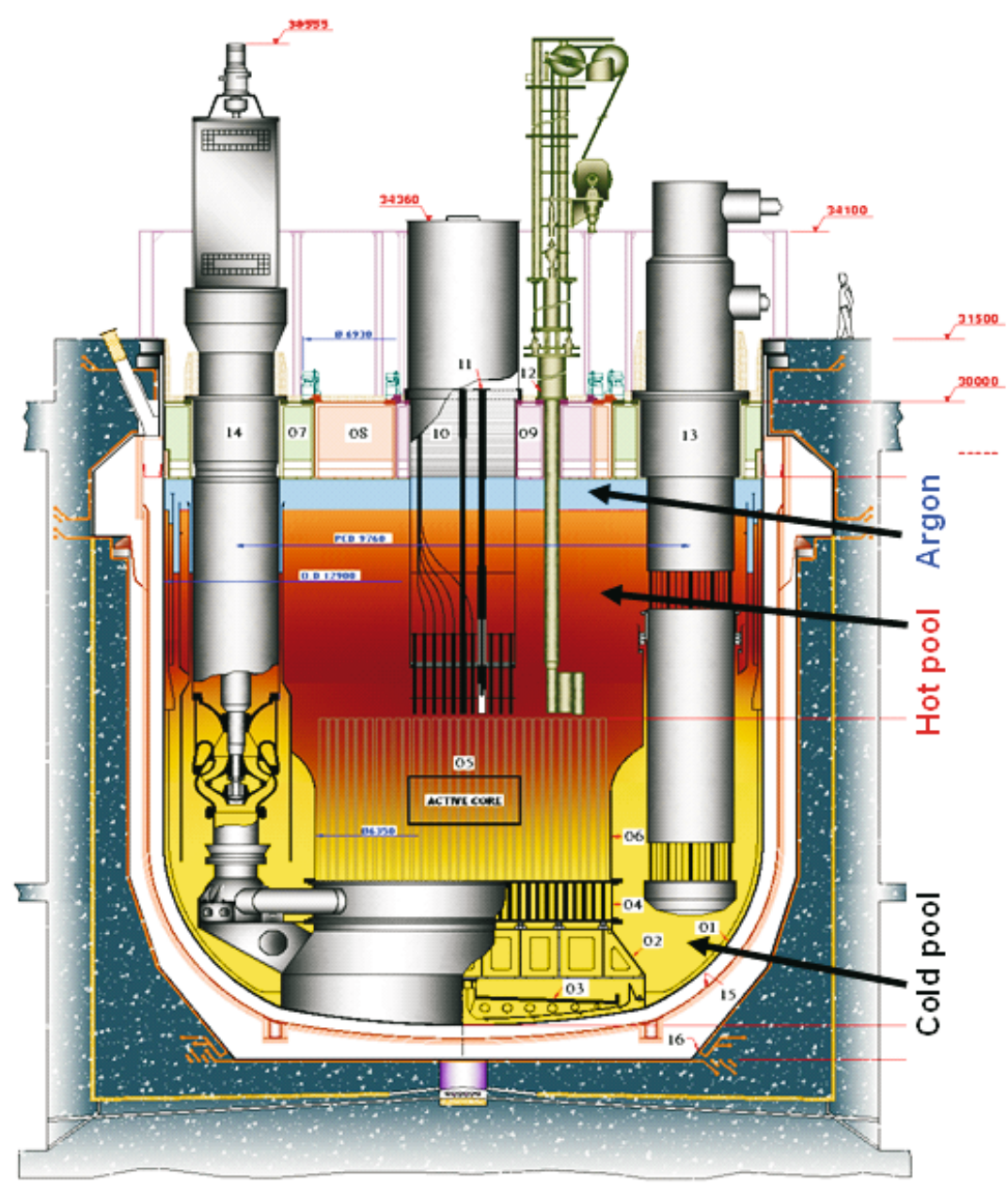

\section{LEGEND}

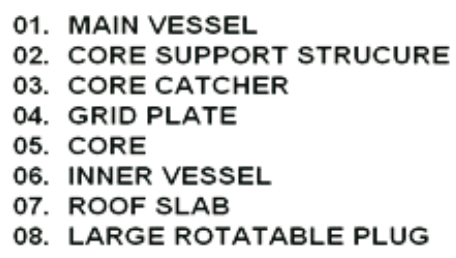

09. SMALL ROTATABLE PLUG

10. CONTROL PLUG

11. CONTROL \& SAFETY ROD MECHANISM

12. IN-VESSEL TRANSFER MACHINE

13. INTERMEDIATE HEAT EXCHANGER

14. PRIMARY SODIUM PUMP

15. SAFETY VESSEL

16. REACTOR VAULT

Figure 2. Reactor assembly of PFBR.

\section{Thermal hydraulic characteristics of PFBR}

Sodium, having a very high heat transfer coefficient $\left(\sim 25,000 \mathrm{~W} / \mathrm{m}^{2} \mathrm{~K}\right)$ in turbulent forced convection regime) is the natural choice as primary heat transport medium. This is essential to remove very high heat flux values $\left(\sim 1.5 \mathrm{MW} / \mathrm{m}^{2}\right)$ encountered in the compact reactor core. Another favourable point for selection of sodium is its high boiling point $\left(880^{\circ} \mathrm{C}\right)$, so that the systems need not be pressurized to achieve high temperature. The operating pressure 
of sodium components, except steam generators is very low $(<1 \mathrm{MPa})$. Hence, the main load on structures is thermal load arising out of high operating temperature (creep), large temperature gradient (thermal stress) and large number of cyclic variations in temperature (thermal fatigue) due to various incidents taking place in the plant. High thermal expansion coefficient and low thermal diffusivity of austenitic stainless steel - SS 316 LN (which is the principal structural material) enhance the severity of thermal transients. Hence, a detailed knowledge of temperature distributions prevailing in the structures is essential for computing the stresses and for life prediction of the structures.

The main drawback of sodium is its violent chemical reaction with air and water. Hence, in all the sodium systems, inert argon gas is maintained above sodium free surfaces to avoid sodium-air contact, as shown in figure 2. Argon also accommodates the volume changes in sodium due to temperature variations. Secondary sodium circuits are employed to avoid entry of hydrogenous materials into the primary sodium. To enhance safety and to contain primary sodium in the unlikely event of main vessel leak, a safety vessel is provided surrounding main vessel. Nitrogen gas is maintained in the $300 \mathrm{~mm}$ annulus between main and safety vessels. On-line sodium and argon leak detection systems are provided in this annulus for early detection of main vessel leak and quick corrective action. Roof slab forms the top cover for main vessel, which is filled with concrete for the purpose of nuclear radiation shielding. It has many narrow penetrations for inserting components like primary pumps, IHX, control plug, etc. The main vessel, roof slab and safety vessel are supported on the reactor vault, which is a concrete structure of about $2 \mathrm{~m}$ thickness, cooled by water. The annular gaps between main vessel, safety vessel and reactor vault are filled with nitrogen gas.

\subsection{Multi-Physics heat transfer}

Thermal conductivity of sodium is very large, about 100 times that of water and 2000 times that of air. As a result of this, the heat transfer coefficient of sodium is very large. This high heat transfer coefficient coupled with thin structural members (stainless steel of thickness $\sim 20 \mathrm{~mm}$ ) leads to Biot number of the order of unity. This calls for a multi-physics (conjugate conduction-convection) heat transfer studies for accurate prediction of structural temperatures. During normal operation, the hot pool (figure 2) is at $550^{\circ} \mathrm{C}$ while roof slab is maintained at $120^{\circ} \mathrm{C}$ and reactor vault is kept below $65^{\circ} \mathrm{C}$. Due to the coexistence of multiple systems of vastly different temperatures having transparent media such as argon/nitrogen transposed between them, thermal radiation heat exchange among the structures is often very important along with convection and conduction heat exchanges.

\subsection{Dominance of buoyancy effects within hot and cold pools}

In a fast reactor with breeder sub-assemblies and internal storage of spent fuel sub-assemblies, temperatures of sodium exiting from fuel $\left(575^{\circ} \mathrm{C}\right)$, breeder $\left(475^{\circ} \mathrm{C}\right)$ and spent $\left(405^{\circ} \mathrm{C}\right)$ subassemblies are vastly different. Due to this temperature difference coupled with large thermal expansion coefficient of sodium $\left(2.8 \times 10^{-4} \mathrm{~K}^{-1}\right)$ and large size of the reactor pool $(12 \mathrm{~m}$ diameter), the Richardson number in the pools is of the order of unity, indicating that the inertial and buoyancy forces are of similar magnitudes. As a result of this, a stratification interface where a large temperature change occurs over a short height is developed (Azarian et al 1990 and Francois et al 1990). The stratification interface is unstable with respect to position and it leads to low frequency $(\sim 0 \cdot 01-2 \mathrm{~Hz})$ temperature oscillations of large amplitude. Since the heat transfer coefficient of sodium is very large, the fluid temperature fluctuations are transmitted to adjoining structures with minimum attenuation. 


\subsection{Complicated flow distributions within Fuel sub-assemblies}

Nuclear heat is generated in the core, which comprises of 181 fuel subassemblies with each assembly having a bundle of 217 fuel pins housed inside a hexagonal wrapper. Cold sodium at $400^{\circ} \mathrm{C}$ is admitted at bottom of the sub-assembly, which flows over pins, absorbs nuclear heat and exits the sub-assembly at $\sim 575^{\circ} \mathrm{C}$. All sub-channels of sodium formed inside the fuel sub-assembly do not have identical hydraulic resistance, which leads to flow by-pass in the peripheral channels between fuel pins and hexagonal wrapper. Also, heat generation rates are not identical in all the pins. These effects lead to flow and temperature mal-distributions inside a sub-assembly. To have an optimum design, realistic estimation of flow characteristics is essential. Computational Fluid Dynamic (CFD) simulation of a whole sub-assembly is very complex, primarily due to a large number of mesh requirements (Gajapathy et al 2007).

\subsection{Thermal stripping}

'Thermal stripping' is a phenomenon, which leads to random temperature fluctuations at the interface between non-isothermal streams, arising out of jet instability (Gelineau \& Sperandio 1994; Tokuhiro \& Kimura 1999). Due to the large heat transfer coefficient associated with liquid sodium, these temperature fluctuations are transmitted to the adjoining structures with minimal attenuation (Wakamatsu et al 1995), which eventually lead to high cycle fatigue and crack initiation in structures. Detailed thermal hydraulic investigation calls for identification of zones prone to thermal stripping and prediction of temperature fluctuations by special modelling techniques.

\subsection{Inter-wrapper flow}

During emergency decay heat removal conditions with DHX dipped inside hot pool, there is strong stratification in the hot pool with interaction of core-outlet and DHX outlet sodium streams. A part of the cold primary sodium exiting from DHX flows to the bottom of the subassemblies (SA) along core periphery and then flows radially inwards and upwards through inter-wrapper space between sub-assemblies. This flow is termed as 'inter-wrapper flow' (Nishimura et al 2000; Mochizuki 2007). A part of the total decay heat generated within the core is transferred to hot pool by sodium passing through the sub-assembly, while the rest of the decay heat is transferred to hot pool by the inter-wrapper flow. The inter-wrapper gap is of the order of $3 \mathrm{~mm}$ while the dimensions of the pool are in terms of $10 \mathrm{~m}$. Prediction of transient evolution of inter-wrapper flow coupled with dynamics of buoyancy driven decay heat removal system is a multi-scale heat transfer problem.

\subsection{Cellular convection of argon in thin annular spaces in top shield}

Argon gas cover is maintained above primary sodium-free level (i) to accommodate volume changes in sodium due to various operating states/transients, (ii) to avoid sodium-air contact and (iii) to reduce heat load to topshield. The topshield is filled with concrete for the purpose of shielding and the temperature of concrete cannot exceed $120^{\circ} \mathrm{C}$. Hence, topshield is cooled by air. The primary sodium temperature in hot pool is $547^{\circ} \mathrm{C}$ during normal operating condition. As a result of these temperature conditions, natural convection of argon takes place, which transports sodium vapour from free level and deposits in colder regions of topshield. Solidification of sodium vapour in colder regions offers difficulties in free movement of the components. Also, heat is transferred to the topshield by thermal radiation as well as 
by natural convection of argon. Due to the narrow gap width of gas spaces, the cellular convection is asymmetric which leads to large circumferential temperature variation in structures that form the annulus and induces thermal stress along with heat load (Velusamy et al 1998).

\subsection{Fluid-structure interaction effects of weir flow}

The volume of primary sodium changes as its temperature, which is a function of reactor power changes. The sodium level difference between the hot and cold pools is a function of primary sodium circulation rate, which is also a function of reactor power. Due to these reasons, sodium levels in the hot and cold pools change. Sodium-free level is a zone of large axial temperature gradient in the structures, which varies with power. Movement of axial temperature gradient in structures, which are highly stressed, leads to 'Thermal ratcheting'. To protect main vessel against this phenomenon, sodium level adjacent to main vessel is maintained constant by an over-flow weir, as a part of main vessel cooling system. The shape of the weir has to be optimized to avoid flow separation at all operating conditions of reactor. When flow separation is avoided, the risk of gas entrainment is minimized. Further, the structural design and flow conditions of over-flow weir have to be such that fluid-elastic instability is avoided.

\subsection{Argon gas entrainment in sodium}

Fast reactor pools are not static and are associated with significant vertical and horizontal velocities. These velocities lead to free level fluctuations and formation of vortices, which are potential sources for gas entrainment in sodium pools. The mechanizms of gas entrainment, gas transportation through heat exchangers (IHX) and pump to grid plate, agglomeration of gas inside grid plate and its passage through core need to be understood well. This is an important safety problem as passage of argon gas through core leads to positive reactivity. It is essential to develop mathematical models that can predict various aspects of gas entrainment, sodium-free surface velocity conditions that can avoid gas entrainment, locations in the grid plate where entrained gas bubbles could segregate and positions of purger sub-assemblies in grid plate and holes in purger sub-assemblies that are conducive for de-gassing of grid plate, without allowing the gas to pass through fuel sub-assemblies.

\section{Thermal hydraulic design limits}

\subsection{Temperature asymmetry in cold pool}

During plant transients associated with one secondary loop, temperature in the cold pool associated with the affected loop becomes hotter or colder than that of the unaffected loop. This leads to circumferential temperature difference in cold pool structures viz. main vessel, grid plate, etc. Flow coast down characteristics of secondary sodium pump (SSP in figure 1) and cold pool capacity need to be arrived at such that the circumferential temperature difference (temperature asymmetry) is less than $30 \mathrm{~K}$ in the structures. Similarly, sodium flow in the main vessel cooling system is to be distributed to respect this temperature asymmetry limit.

\subsection{Free level fluctuation}

Due to large surface area $\left(>100 \mathrm{~m}^{2}\right)$ interfacing with argon, hot pool free surface oscillates. Height of inner vessel above mean hot pool sodium level should be adequate to avoid overflow 
of hot pool sodium to cold pool. The amplitude of fluctuation has to be minimum so that the height of inner vessel can be minimum. Nominal temperature of hot pool is $547^{\circ} \mathrm{C}$ and that of argon cover gas is $430^{\circ} \mathrm{C}$. When the level fluctuates, structures partly immersed in hot pool and partly exposed to cover gas see alternating temperatures. From high cycle fatigue considerations, the amplitude of fluctuations has to be less than $50 \mathrm{~mm}$.

\subsection{Free surface velocity in pool}

To avoid stratification risk in the pool, sodium velocity in bottom part of the pool has to be high. At the same time, velocity at the free surface has to be limited to $0.5 \mathrm{~m} / \mathrm{s}$ to avoid gas entrainment. Entrainment of gas has to be limited to the extent that it does not cause any reactivity changes in core. Continuous limited flow of argon through core is not of any serious concern. But segregation of minute bubbles in grid plate to agglomerate into a larger bubble and its sudden movement into core is to be avoided.

\subsection{High-cycle temperature fluctuation}

The extent of stratification in hot pool is a function of ratio of buoyancy forces to inertial forces. Stronger the inertial forces, the lower will be axial temperature gradient. The stratification interface normally oscillates. Based on detailed structural mechanics calculations, it has been established that the gradient has to be limited to $<300 \mathrm{~K} / \mathrm{m}$. From thermal stripping considerations, the peak to peak temperature fluctuations on structures has to be limited to $60 \mathrm{~K}$ for control plug and $40 \mathrm{~K}$ for main vessel and inner vessel.

\subsection{Heat loss to top shield}

The heat loss to top shield has to be minimum to minimize the heat load on top shield cooling circuit. By the provision of thermal shield, direct radiation heat load and argon convection heat load are reduced by $\sim 50 \%$. But this in-turn increases the bulk temperature of argon cover gas. Increase in bulk temperature will enhance cellular convection and the associated temperature asymmetry. The bulk cover gas temperature will also affect axial temperature gradient in the structures. Cellular convection of argon in narrow gap penetrations of top shield has to be managed to have temperature asymmetry less than $30 \mathrm{~K}$. Annular gap size and cooling conditions of top shield are to be optimized to respect this limit.

\section{Analysis methods}

The above-discussed thermal hydraulic problems can be analysed either by experimental simulations or by numerical simulations. Since sodium reacts violently with air and water with potential consequences, sodium experiments need to be designed with extra care for safety. Moreover, sodium is in liquid phase only above $98^{\circ} \mathrm{C}$. Hence, sodium experiments have to be performed at elevated temperatures. To compound these difficulties, sodium is opaque and hence flow visualization is difficult. Thus, large-scale experiments in sodium are costly and time consuming. Normal fluids like air and water cannot simulate sodium conditions for heat transfer, due to large difference in the values of their Prandtl numbers. But, hydraulic conditions of sodium can be nearly simulated by water models. Even to simulate thermal hydraulic processes taking place in gases, such as argon and nitrogen, numerical simulation is cheaper and faster especially when the number of parameters involved is large. 
But, numerical models and the codes developed need to be validated by suitable experiments. For a successful design, a judicious combination of experimental and numerical approaches is a must. The method adopted in design of PFBR is based on performing many large-scale water experiments and limited sodium experiments to validate computer codes and then using these validated computer codes for numerical prediction of sodium flow and temperature distributions in the reactor.

\section{Thermal hydraulic codes}

Thermal hydraulic characteristics of fast breeder reactors are very complex with a variety of special phenomena. These phenomena have been investigated by a combination of commercial CFD codes and in-house CFD codes. Different phenomena are well simulated by different codes. For example, to simulate a shell and tube heat exchanger with large number of tubes by a porous body model, the PHOENICS code is well-suited due to its capability for independent definition of surface porosities in various directions along with volumetric porosity. This leads to prediction of actual velocity components in different directions, while other CFD codes deal with superficial velocity components in porous media. CFD code like STAR-CD is powerful to model flows with complex geometries due to its unstructured mesh capability. Since, a fast reactor has a large number of systems/components, multiple agencies are involved in the prediction of thermal hydraulic parameters. Since, these agencies have expertise in different CFD codes, all the components are not analysed with a single CFD code.

For multidimensional fluid flow and heat transfer analyses, two computer codes THYC-2D (Rajakumar et al 1987) and THYC-3D (Asokkumar 1990) have been developed in-house. They respectively solve 2 and 3 dimensional Navier-Stokes and energy equations in Cartesian and cylindrical coordinate systems (Hughes \& Gaylord 1964) using a control volume based discretisation method. Boussinesq approximation is used to take care of buoyancy effects. Turbulence is modelled using the standard $k-\varepsilon$ model (Launder \& Spalding 1974). Porous body formulation is used to model submerged small-scale structures. The governing equations are:

Continuity:

$$
\nabla \bullet\left(\rho \beta_{S} \bar{V}\right)=0 .
$$

Momentum:

$$
\nabla \bullet\left(\rho \bar{V} \beta_{S} \phi\right)=\nabla \bullet\left(\mu_{\mathrm{eff}} \beta_{S} \nabla \phi\right)+\beta_{V} S_{\phi} .
$$

Energy:

$$
\nabla \bullet\left(\rho C_{P} \bar{V} \beta_{S} T\right)=\nabla \bullet\left(K_{\mathrm{eff}} \beta_{S} \nabla \phi\right)+\beta_{V} S_{T} .
$$

Turbulent Kinetic Energy:

$$
\nabla \bullet\left(\rho \bar{V} \beta_{S} k\right)=\nabla \bullet\left(\left[\mu+\frac{\mu_{t}}{\sigma_{k}}\right] \beta_{S} \nabla k\right)+\beta_{V} S_{k} .
$$


Turbulence Dissipation Rate:

$$
\nabla \bullet\left(\rho \bar{V} \beta_{S} \varepsilon\right)=\nabla \bullet\left(\left[\mu+\frac{\mu_{t}}{\sigma_{\varepsilon}}\right] \beta_{S} \nabla \varepsilon\right)+\beta_{V} S_{\varepsilon} .
$$

In the above equations, $\rho$ is density, $\beta_{S}$ is surface porosity, $\beta_{V}$ is volumetric porosity, $\bar{V}$ is velocity vector, $\phi$ represents velocity components in different coordinate directions, $\mu$ is laminar viscosity, $\mu_{t}\left(=\rho C_{\mu} k^{2} / \varepsilon\right)$ is turbulent viscosity, $\mu_{\text {eff }}\left(=\mu+\mu_{t}\right)$ is effective viscosity, $S_{\phi}$ is source term including pressure gradient and buoyancy terms, $C_{P}$ is specific heat, $T$ is temperature, $K$ is laminar thermal conductivity, $K_{t}\left(=\mu_{t} C_{P} / \sigma_{T}\right)$ is turbulent thermal conductivity, $K_{\text {eff }}\left(=K+K_{t}\right)$ is effective thermal conductivity, $S_{T}$ is source term including heat generation/heat sink, $S_{k}$ and $S_{\varepsilon}$ are source terms in $k$ and $\varepsilon$ equations, $C_{\mu}$ is turbulence model constant $(=0.09)$, and $\sigma_{T}, \sigma_{k}$ and $\sigma_{\varepsilon}$ are turbulent Prandtl numbers having values 1.0, 1.0 and 1.3 respectively.

The pressure-velocity coupling is resolved either by the SIMPLE algorithm (Patankar 1980) or one of its variants viz. SIMPLER, SIMPLEC and SIMPLEST algorithms. The convective and diffusive fluxes are combined by Upwind, Hybrid or Power-law schemes. The discretisation equations are solved by Tri-Diagonal Matrix Algorithm and its extended forms for penta and septa diagonal matrices, employing multi-directional sweeps. These codes have been validated against numerical/experimental results published in open literature and experiments carried out in-house.

\subsection{Validation of computer codes}

Formulations of the in-house computer codes and usage of commercial codes have been validated by solving standard problems such as, flow in lid driven cavities, flow development in ducts, flow over a backward facing step, natural convection in enclosures, etc. for which benchmark results are published in open literature. In addition to this, predictions of these codes are compared against experiments carried out in-house.

Velocity distribution at the entry to intermediate heat exchanger inlet windows, predicted by PHOENICS code (version 3.5) and the same extrapolated to reactor based on 1/4 scale water model tests carried out at IGCAR are compared in figure 3. In this figure, 'Theta' refers to the circumferential location around IHX. IHX-1, 3 and 4 refer to four IHXs in reactor and experimental model. Due to symmetry, numerical result is the same for all the IHXs. It can be seen that the maximum deviation between numerical and mean experimental data is about $10 \%$. Considering the industrial natural of the problem, the comparison is quite satisfactory.

Mixing characteristics of multiple jets entering into main vessel cooling annulus of PFBR have been studied in a 1/5 scale water model. The slab model has 3 jets. Flow visualization in the model has been carried out by simultaneous dye injection at multiple points coupled with digital photography. The model has also been numerically simulated in the CFD code PHOENICS (version 3.5) for the purpose of validating the code. Flow patterns in the model were observed for full and $20 \%$ flow conditions. The CFD study is a 3-D turbulent steady flow simulation. Cooling jets were found not to spread uniformly even for $20 \%$ flow condition where the jet velocity is small. The jets travel up to free surface generating large zones of recirculation in the annulus. The flow patterns observed for full and $20 \%$ power conditions were identical. It was seen that in all the cases studied, the flow patterns predicted by the PHOENICS code matched very well with experimentally observed flow patterns (figure 4), validating the code and its usage for main vessel cooling calculations. 


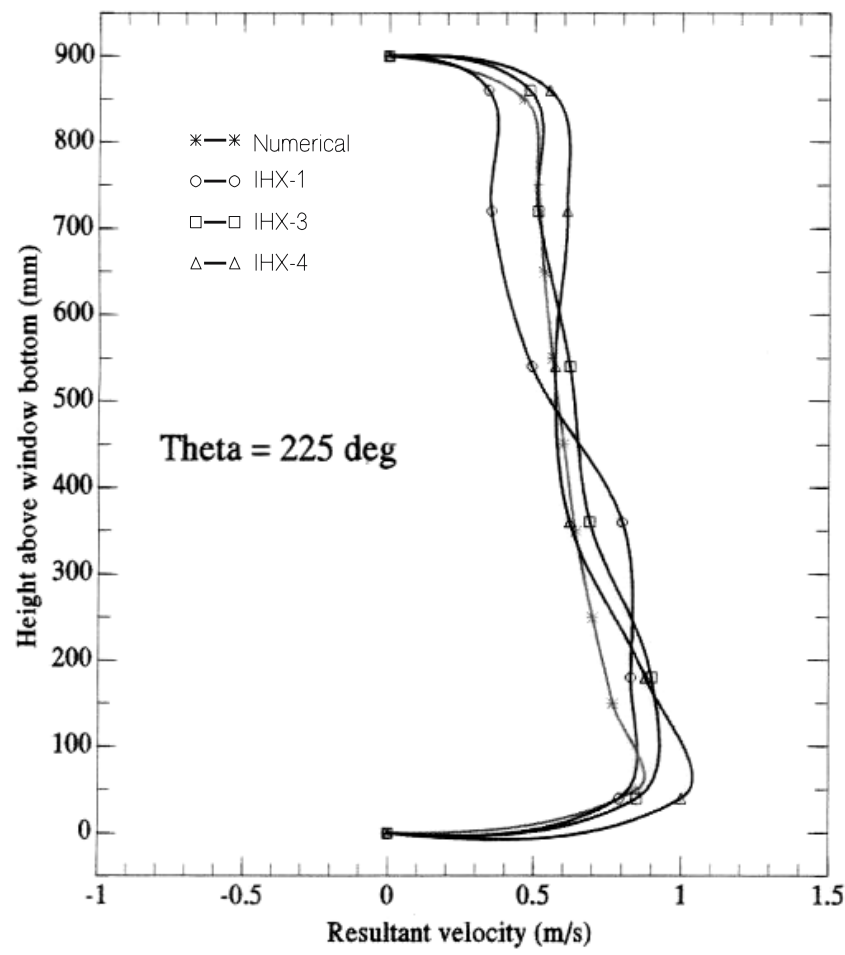

Figure 3. Comparison of measured and predicted velocity distributions at entry to IHX primary inlet windows.

Heat transfer experiments have been carried out in Japan in a main vessel cooling model of Demonstration Fast Breeder Reactor (Kamzaki et al 1995). Temperature distributions in the cooling baffles and in sodium have been measured at various heights of the cooling system. This system has been numerically simulated in THYC-2D code. Temperature distributions predicted by the code at various elevations are compared against reported measurements in figure 5. The maximum difference between the two results is about $5 \%$ for baffle temperatures, which is quite reasonable. More details about this study can be had from (Velusamy et al 1997).

\section{Results and discussion}

\subsection{Investigation of stratification in hot pool}

3-D flow and temperature distributions of primary sodium in hot pool under various power levels have been predicted using PHOENICS code (version 3.5). This code is preferred over other codes due to its superior porous body model capability for IHX and control plug and flexible user coding for additional momentum sinks. In the reference design, the pool is stratified even at full power condition, as depicted in figures $6 a$ and $b$. The Richardson number $(R i)$ in this case is $\sim 0 \cdot 25$. It is the ratio of buoyancy force to inertial force, defined as $R i=$ $\frac{\beta g \Delta T D}{V^{2}}$, where $\beta$ is volumetric expansion coefficient of sodium (typically $2.8 \times 10^{4} \mathrm{~K}^{-1}$ ), $g$ is acceleration due to gravity, $\Delta T$ is maximum temperature difference among various sodium streams $(175 \mathrm{~K}), D$ is distance between SA-top and core cover plate (1.2 $\mathrm{m}$ in case of PFBR) and $V$ is sodium velocity entering hot pool through the gap between SA-top and core cover 


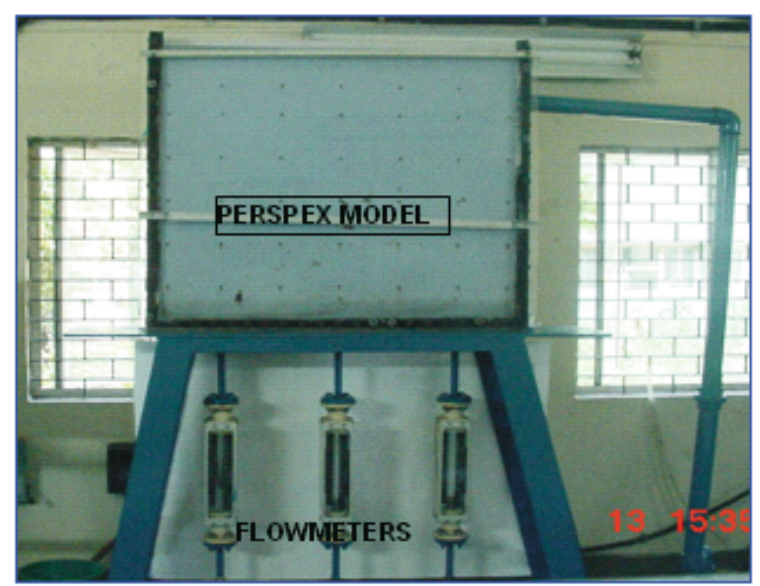

(a)

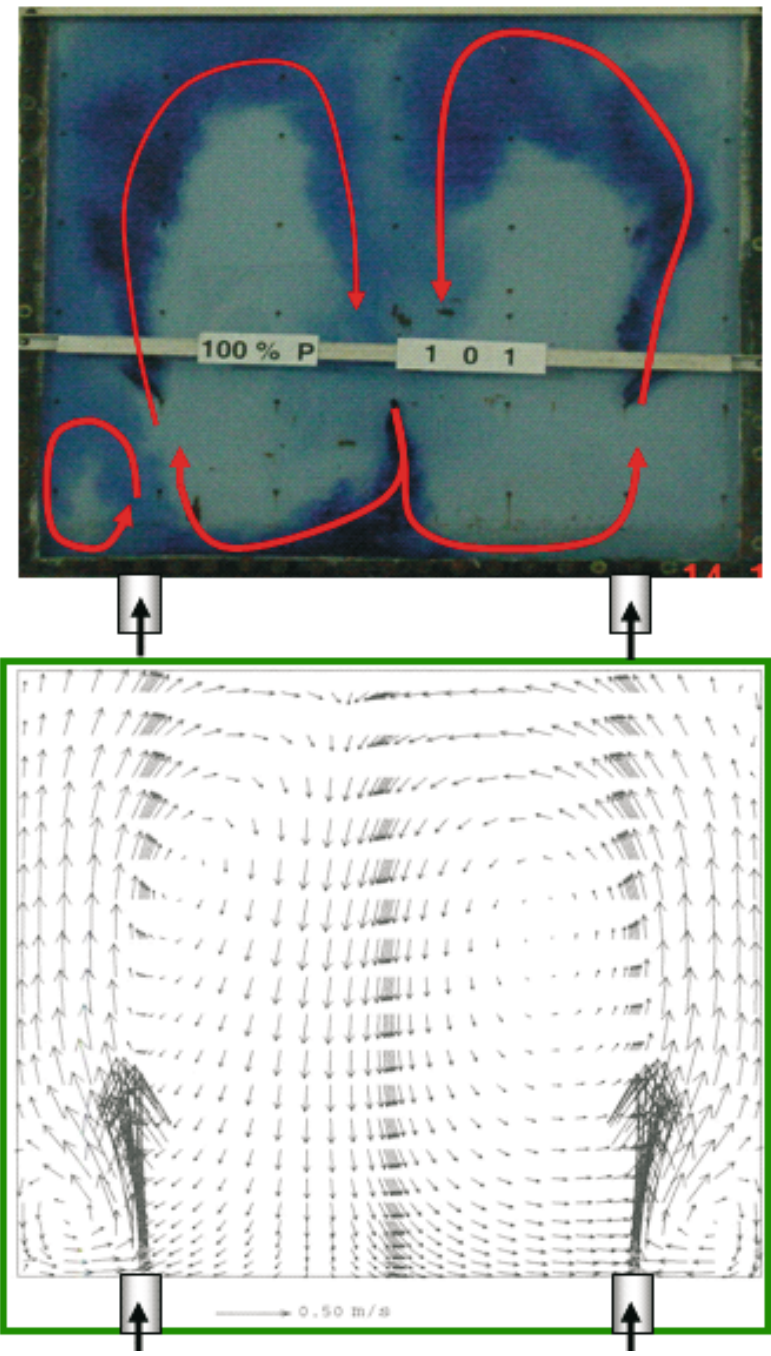

(b)

(c)

Figure 4. Validation of flow distribution in main vessel cooling system: (a) experimental setup, (b) observed flow pattern and (c) flow pattern predicted by 3-D CFD study. 


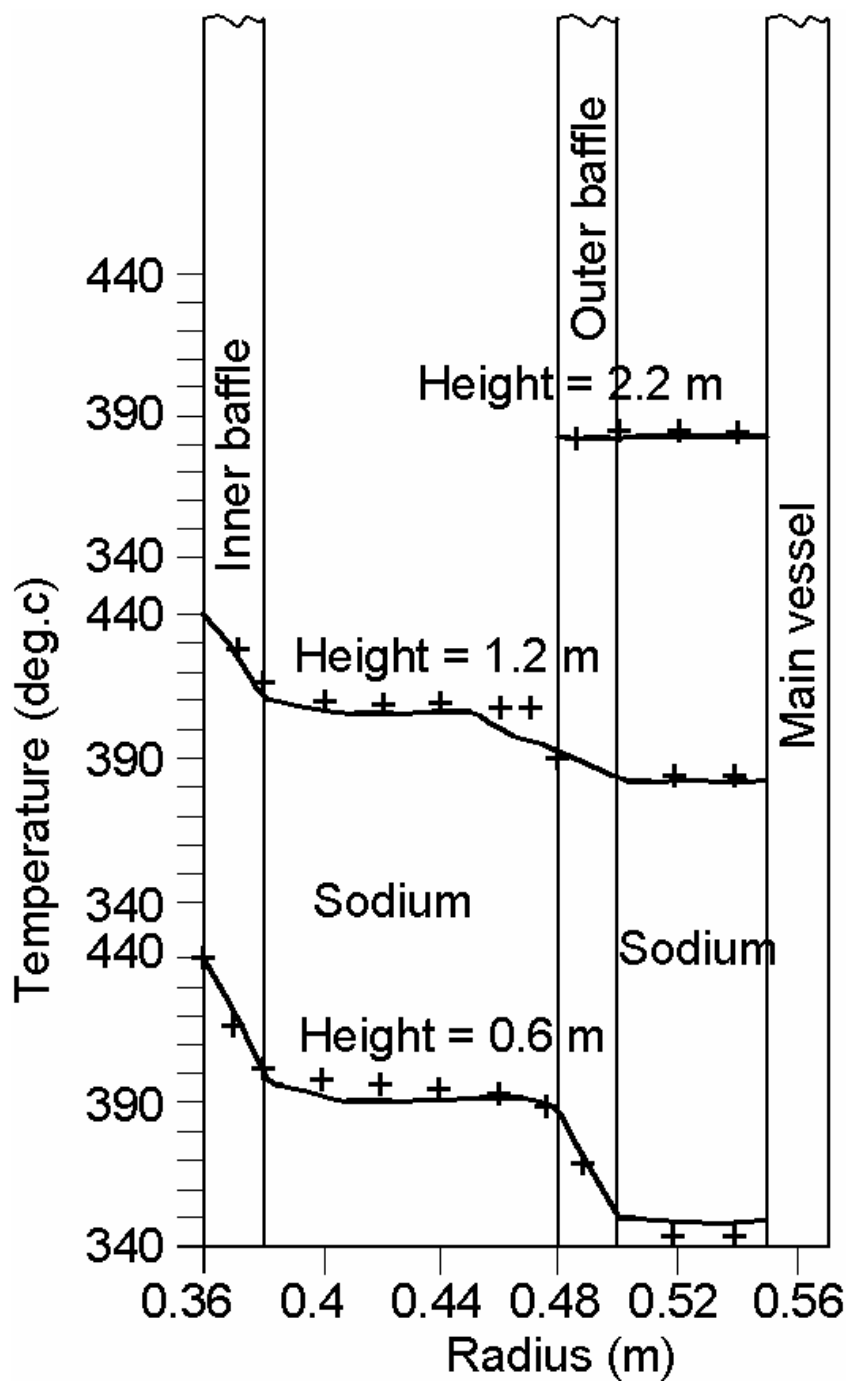

Figure 5. Comparison of predicted and measured temperature distributions in main vessel cooling system of demonstration fast breeder reactor (solid line: CFD calculation and + : measurement).

plate. To reduce the Richardson number and thereby break stratification, radial velocity of sodium entering the pool has been increased by providing a skirt below the control plug. The flow and temperature distributions after this modification are depicted in figures $7 \mathrm{a}$ and $\mathrm{b}$. The Richardson number with skirt is $\sim 0.065$ and it can be seen that there is no stratification in hot pool. Similar thermal hydraulic study was carried out at low power conditions also. In order to have a high steam temperature and hence high efficiency, it is felt that the core flow be reduced proportional to reactor power, maintaining the temperature increase across the core as $150 \mathrm{~K}$ (same as that at full power). Even with the skirt, the hot pool was found to be stratified at low power, when sodium velocity is low. In order to take care of this, 'low power operation strategy' has been modified. As per this strategy, the primary sodium flow rate at low power is modified to have a Richardson number of $\sim 0.065$ (same as that at full power). In this strategy, primary sodium flow through core is not proportional to reactor power. The flow fraction at part load condition (and hence $V$ ) is always more than the power fraction. 


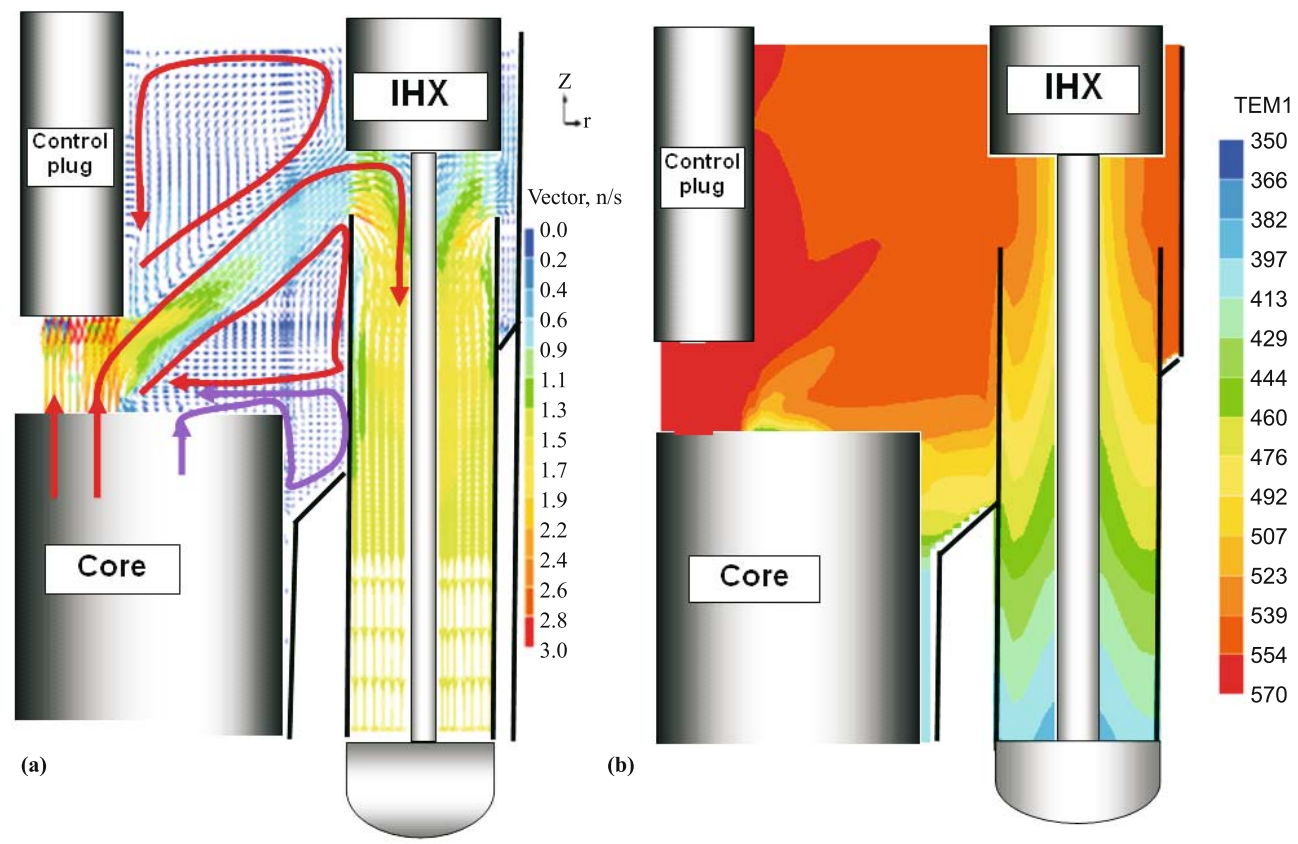

Figure 6. (a) Flow field in hot pool at full power (Reference case). (b) Temperature $\left({ }^{\circ} \mathrm{C}\right)$ field in hot pool at full power (reference case).
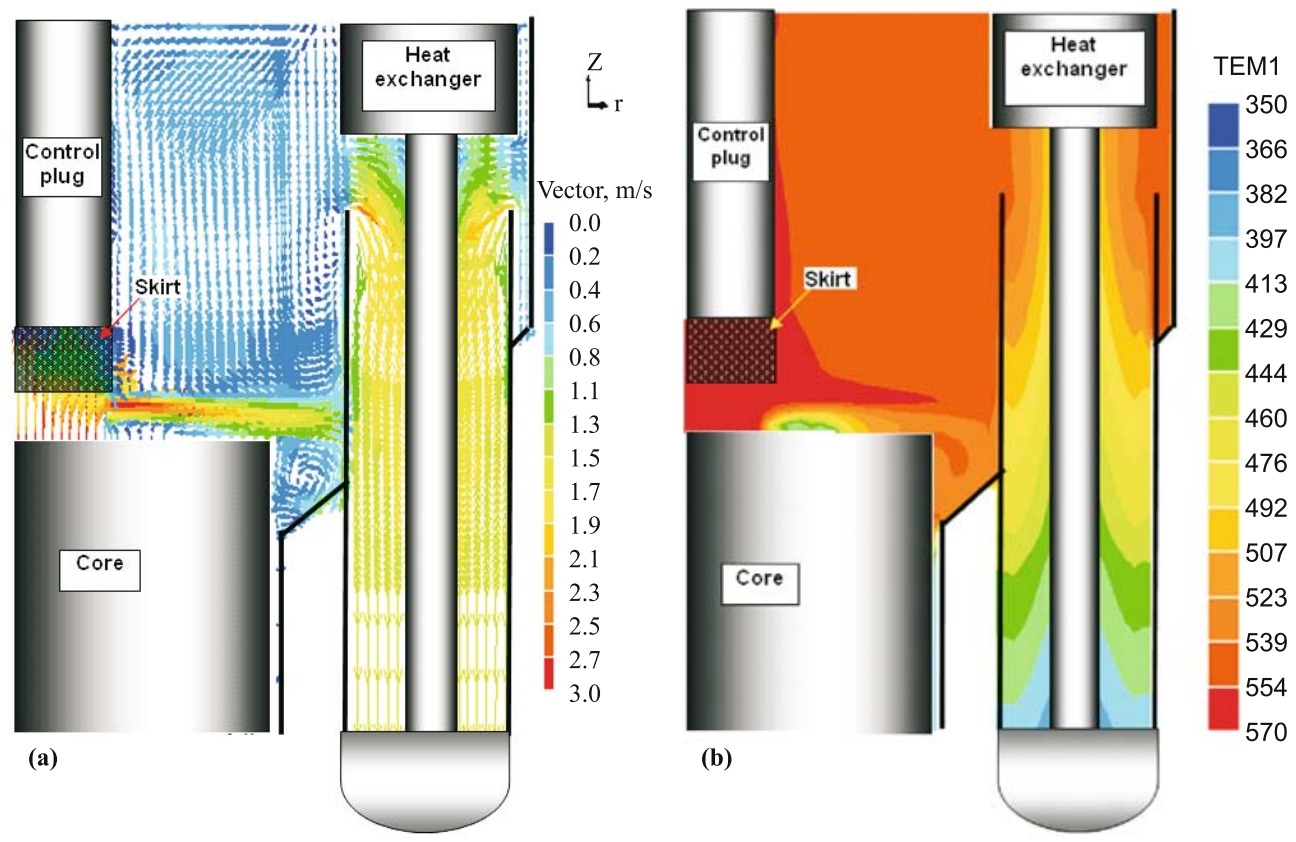

Figure 7. (a) Flow field in hot pool at full power (Design with skirt). (b) Temperature $\left({ }^{\circ} \mathrm{C}\right)$ field in hot pool at full power (Design with skirt). 


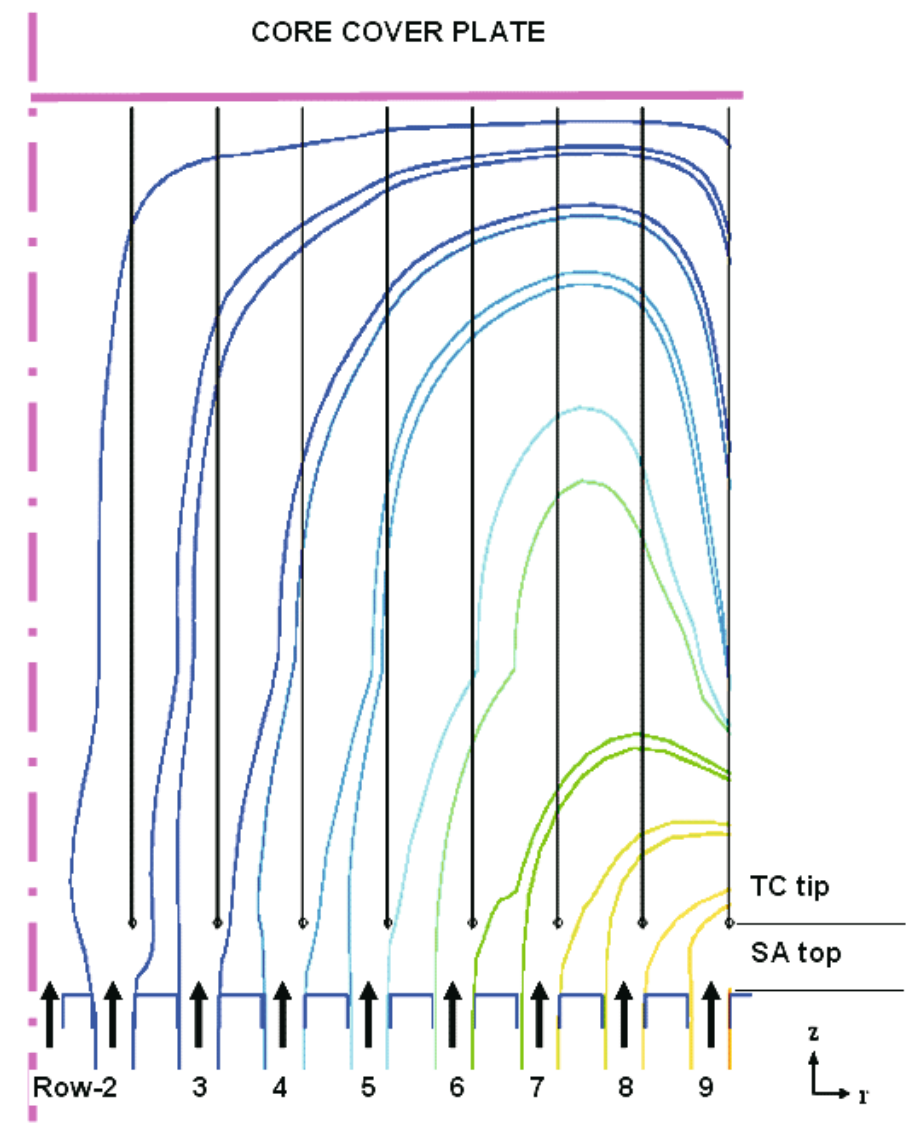

Figure 8. Stream lines below core cover plate at full power along with thermocouples (TC).

As a result of this, $\Delta T$ is less at low power than at full power. Since, $R i \propto \Delta T / V^{2}$, this ratio is maintained same at all power conditions of the core.

\subsection{Core temperature monitoring}

Temperature of sodium exiting from all the fuel and inner row of breeder SA are coninuously monitored to check the adequacy of core cooling and to take timely safety action. The temperatures of $210 \mathrm{SA}$ are to be monitored by using thermocouples. Since these 210 sodium jets interact below the control plug, it is essential that the individual temperatures are measured accurately before they mix. For accurate temperature measurement, the clearance has to be as minimal as possible. But from the considerations of axial swelling of SA due to irradiation, thermal expansion of components, free rotation of control plug during fuel handling and under sodium viewing, the clearance has to be as large as possible. Provision of the skirt (to avoid stratification as discussed in section 6.1) at the bottom of control plug has an adverse effect of deflecting sodium streams and leading to deterioration of temperature signal. This calls for a detailed prediction of flow paths taken by sodium streams from various SA, the movement of thermocouples and SA due to irradiation-induced swelling, manufaturing tolerence, etc. Towards this, the axial distance between SA-top and control plug bottom has been 
varied as a parameter in the 2-D axi-symmetric CFD calculations by PHOENICS code (version 3.5), for various reactor power conditions. From the predicted distributions of velocity and temperature, the optimum distance between SA-top and thermocouple bottom has been arrived at as $100 \mathrm{~mm}$. Since sodium streams bend outwards, centrelines of thermocouples are shifted raidially outward by $20 \mathrm{~mm}$ from the respective SA centrelines. Sodium stream paths and thermowell locations for this chosen option are depicted in figure 8, as predicted by PHOENICS code. It is seen that thermowells of all the SA are immersed in their respective streams, with this arrangement, at all the operating power conditions.

It is essential to ensure an automatic safety action by the reactor protection system (i.e. automatic shutdown of the reactor), in the event of a flow blockage developing in any SA. Towards this, 2-D axi-symmetric steady state thermal hydraulic analysis has been carried out consideing flow blockage in individual SA. A reudction in sodium flow is accompanied by asscoiated increase in sodium outlet temperature from the affected SA. In this analysis, the extent of flow blockage in each SA is varied as a parameter and increase in sodium temperature at thermocouple tip (above that at normal conditions) is predicted. If this value exceeds $5 \mathrm{~K}$, there will be alarm in the plant and if it exceeds $10 \mathrm{~K}$ the reactor will trip. From this, it has been established that a flow reduction of 6-8\% would be promplty detected by the thermocouples to trip the reactor. However, from fuel clad failure considerations, the permissible flow reduction is much higher (30\%). Thus, the safety of the core is assured with large safety margin.

\subsection{Prediction of thermal stripping}

Due to the difference in the heat generation rates among fuel, breeder and spent fuel SA, the temperatures of sodium jets leaving them are not the same. Thermal stripping takes place due to oscillations in non-isothermal jet flows. Detailed thermal hydraulic investigation has been carried out to quantify the amplitude and frequency of temperature fluctuations in the structures of primary sodium system. The investigation consists of CFD simulations at two levels. In the first level, locations prone to thermal stripping were identified, by performing a global conjugate 3-D simulation of hot and cold pools, employing the standard k- $\varepsilon$ turbulence model, using the commercial CFD code FLUENT (version 6.0). This code is adopted due to its superior capability to model irregular geometry of the hot pool with IHX and pumps employing an unstructured mesh. In this study, a $90^{\circ}$ symmetric sector of hot and cold pools consisting of one IHX, a half primary sodium pump, and a quarter of core has been considered, to determine steady state flow and temperature distributions and to localize regions having large temperature gradients. In the $2^{\text {nd }}$ level, transient transport equations were solved by Direct Numerical Simulation (DNS) method, using the FLUENT code, to predict flow and temperature fluctuations. Temperature fluctuation in the fluid medium is caused by generation of large eddies which ultimately degenerate to smaller ones. There is a strong correlation between the size/frequency of eddies and the amplitude/frequency of temperature fluctuations. Use of either Large Eddy Simulation (LES) or DNS is required to capture these fluctuations in turbulent flow simulations. From the global simulation at full power condition, the heat transfer from hot pool to cold pool has been estimated as $12 \mathrm{MW}$ and the maximum temperature difference across inner vessel ( $20 \mathrm{~mm}$ thick) is determined to be $60 \mathrm{~K}$. The temperature variation in primary sodium entering IHX is found to be less than $2 \mathrm{~K}$. The axial temperature variation in sodium leaving IHX window in the cold pool is found to be $40 \mathrm{~K}$, due to flow bypass effect.

From the global study, four zones have been identified as having potential for thermal stripping. The zones are viz. (a) fuel - breeder SA sodium mixing interface, (b) fuel - control SA sodium interface, (c) stratification at redan - lower shell junction and (d) primary sodium outlet from IHX. Zones (a) and (b) are below the core cover plate in hot pool, zone (c) is near 

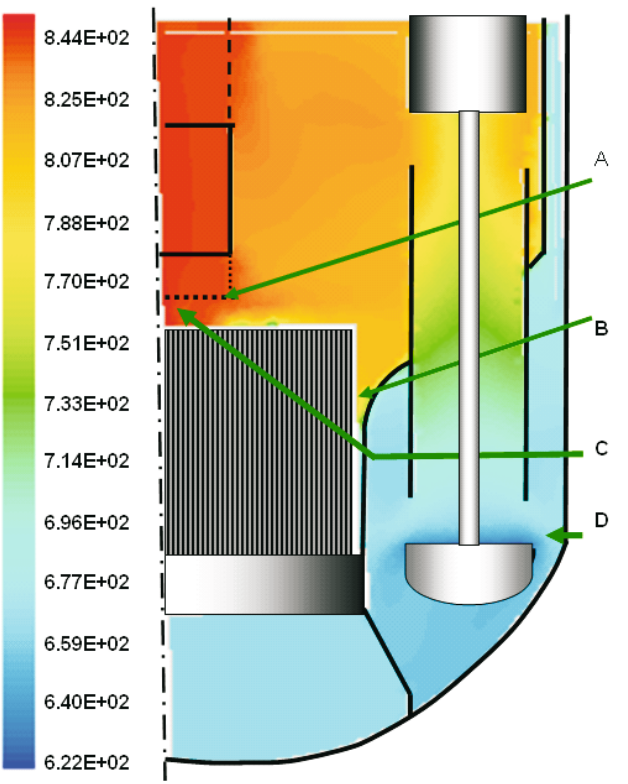

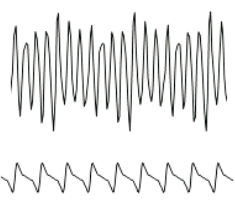

Fuel/Breeder interface-A $\triangle T$ sodium: $60 \mathrm{~K}$

Stratification near inner vessel - B $\triangle T$ sodium: $15 \mathrm{~K}$

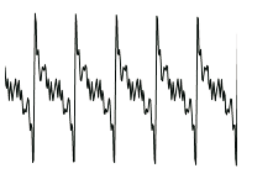

Fuel / Control rod interface - C $\Delta \mathrm{T}$ sodium: $98 \mathrm{~K}$

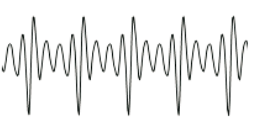

Main Vessel near IHX-exit - D $\Delta T$ sodium: $40 \mathrm{~K}$

Figure 9. Global temperature (K) distribution in sodium and peak-to-peak sodium temperature fluctuation.

inner vessel and zone (d) is in cold pool. DNS calculations have been performed for these local zones employing very fine grids $(\sim 0.1 \mathrm{~mm}$ size $)$ and very small time steps $(\sim 1 \mathrm{~ms})$. From the DNS simulations, sodium temperature fluctuations and surface temperature fluctuations have been obtained. The computed peak-to-peak values of sodium temperature fluctuations are depicted in figure 9 for various zones. The peak-to-peak sodium temperature fluctuation is $60 \mathrm{~K}$ for control plug parts, $98 \mathrm{~K}$ for control rod drive mechanism shrouds, $15 \mathrm{~K}$ for inner vessel and $40 \mathrm{~K}$ for main vessel. The attenuation within thermal boundary layer was found to be in the range of 50-60\%. Eventually, the peak-to-peak temperature fluctuation on the surface is $22 \mathrm{~K}$ for control plug parts, $48 \mathrm{~K}$ for control rod shrouds, $9 \mathrm{~K}$ for inner vessel and $20 \mathrm{~K}$ for main vessel (Velusamy et al 2005). The frequency of temperature fluctuations was found to be in the range of $2-40 \mathrm{~Hz}$. Detailed structural mechanics calculations indicate that the acceptable peak-to-peak structural temperature variation is $60 \mathrm{~K}$ for control plug structures and $40 \mathrm{~K}$ for inner and main vessels, establishing that there is no risk of thermal stripping damage for PFBR structures.

\subsection{Thermal hydraulic design of main vessel cooling system}

Main vessel is an important structure of PFBR. From the considerations of compatibility with sodium and high temperature strength, it is made up of SS-316, which undergoes considerable creep damage at temperatures greater than $480^{\circ} \mathrm{C}$. Since the mean temperature of hot pool is $\sim 550^{\circ} \mathrm{C}$, the vessel temperature is bound to approach this value due to continuous heat leak from hot pool to cold pool through inner vessel. Hence, a separate cooling system is envisaged for the main vessel, as depicted in figure 10a. It consists of two concentric cylindrical baffles, attached to the inner surface of main vessel. Sodium from cold pool is pumped into the outer annulus (between main vessel and outer baffle). It overflows into the inner annulus (between the outer and inner baffles) and leaves back to cold pool. The upper shell of inner vessel, 


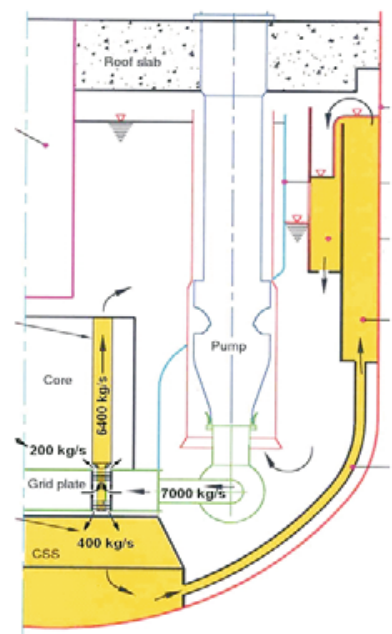

(a)
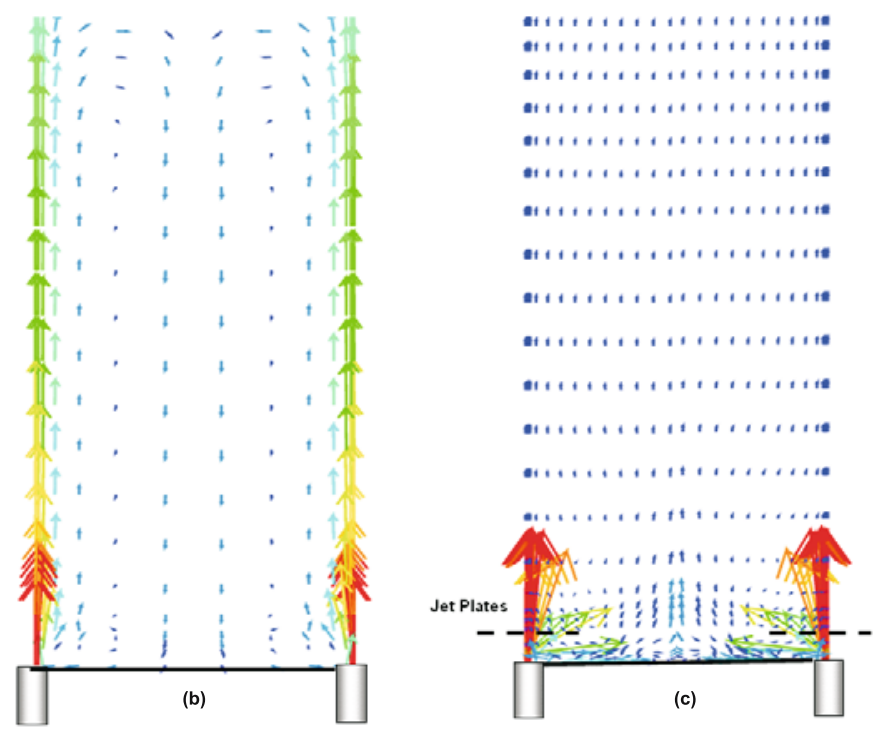

Figure 10. CFD studies towards finalizing main vessel cooling system: (a) schematic of the system, (b) flow field in reference design and (c) flow field with jet breakers to have uniform cooling.

cooling baffles and main vessel form a multiple enclosure filled with sodium. Based on detailed thermal hydraulic assessment of circumferential temperature non-uniformity and jet spread characteristics, design of a jet breaker plate has been arrived at (Velusamy et al 2002). Due to large diameter of the annulus $(\sim 12.5 \mathrm{~m})$ and the associated manufacturing tolerances, the annulus gap is expected to have a variation of $\pm 30 \mathrm{~mm}$ over nominal value of $90 \mathrm{~mm}$. With jet breaker plates in position, this large variation in gap is found to be acceptable from uniform cooling of main vessel. Figure $10 \mathrm{~b}$ depicts flow distribution of cooling sodium inside the annulus in reference design, as predicted by PHOENICS code (version 3.5). It is evident that there is large flow mal-distribution with non-uniform cooling. With jet breaker plates the flow distribution has become almost uniform, as seen in figure 10c. Effects of one coolant pipe blockage as well as rupture of one cooling pipe (and the associated loss of cooling) have been studied in detail for various power conditions of the reactor. Based on the study, it has been established that even under these extremely unlikely conditions, cooling of main vessel is not affected significantly.

\subsection{Optimization of spherical header}

Primary sodium from cold pool is sucked by two sodium pumps operating in parallel, delivering $7000 \mathrm{~kg} / \mathrm{s}$ at a head of 75 metres of liquid column (mlc). Sodium from each of these pumps enters a spherical header, where it branches into two streams to two primary pipes before entering grid plate. Grid plate is a high pressure plenum which distributes sodium to various sub-assemblies where nuclear heat is generated. The header is spherical in shape to respect space constraints in cold pool. Spherical shape is also chosen to have point contact with core support structure and to have relatively free slide between the header and core support structure in the case of transients that differentially affect cold pool structures. It is essential to minimize pressure loss in the 'header-primary pipe' assembly, in order to have a lower head developed by the pump. The pressure loss in this system needs to be evaluated from 

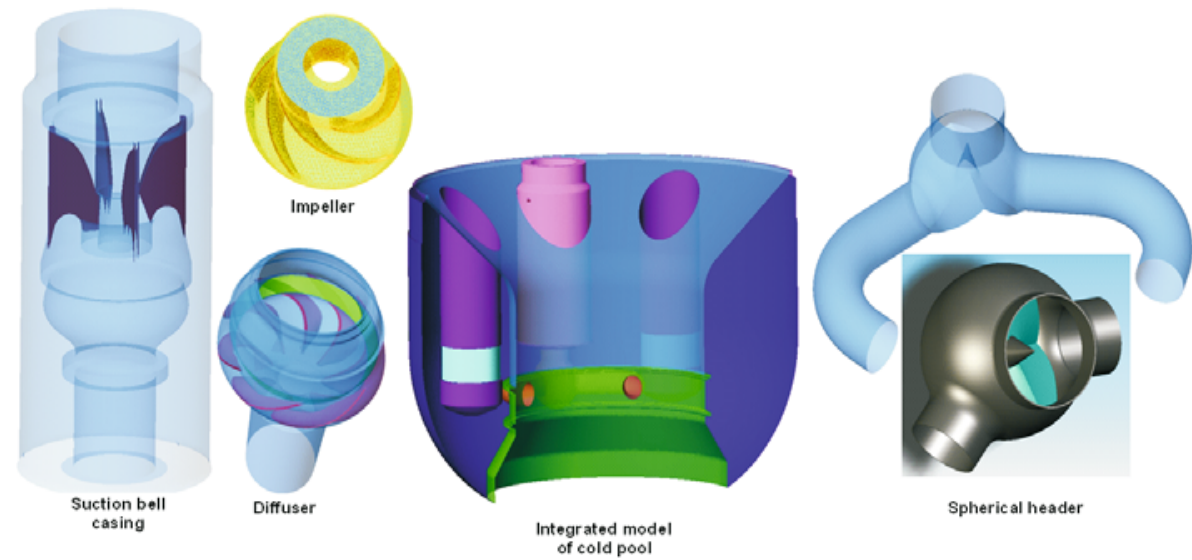

Figure 11. Integrated CFD model of PFBR cold pool and primary sodium pump.

first principles. Towards this, various internal baffle options have been studied as a parametric study, which includes baffles coupled with a central cone. Computational domain for the integrated CFD analysis extends from heat exchanger outlet windows in cold pool to grid plate inlet, comprising two heat exchangers and one primary sodium pump. Along with cold pool, pump suction casing, pump impeller, pump diffuser, pump discharge pipe, spherical header with flow distribution baffles and primary pipes have been modelled in detail with over 30 lakhs mesh points in the CFD code (figure 11), CFX (version 5·7.1). Traditionally, CFX code is being employed successfully for hydraulic analysis of pumps with rotating impellers and hence, it is adopted in the present application also. The computed static pressure distributions and streamlines in a vertical section of the header, for three different configurations are depicted in figure 12. It is clear that there is a vast recirculation zone in the blank header with large magnitudes of velocity (figure 12a). For the optimised header (figure 12c), stream lines indicate that sodium smoothly enters the primary pipe with minimum pressure loss in the header. The computed pressure loss coefficient in the blank header is 7.2 and that with baffles and central cone is $1 \cdot 2$, suggesting that the pressure loss is reduced by a factor of 6 .

Numerically predicted pressure loss is also validated by performing experiments in a 1:3 scaled down air model, which is depicted in figure 13. In air model studies, geometric similarity is observed, maintaining Reynolds number in turbulent regime. Experiments have been conducted on two header models, viz. basic (blank) header and header with internal baffles, optimised though the parametric CFD study with CFX code, discussed earlier. The pressure loss coefficients measured in the experiments are 6.0 for blank header and 1.2 for header with baffles, thus validating the computations (Velusamy et al 2007). The deviation between the measured value and the value obtained by CFX code is $20 \%$ for blank header and negligibly small for header with internal baffles.

\subsection{Flow distribution in grid plate}

Heat generation rate inside a fuel SA depends on its location in the core and its enrichment. To achieve a nearly uniform sodium outlet temperature from all the fuel SA, the flow rate in each SA is modified, by providing suitable orifices. To decide upon the orifice for various SA, knowledge of pressure distribution inside the grid plate, which feeds all the SA is essential. Also, the perforated cylindrical sleeves (1758 Nos.) which support the SA are 

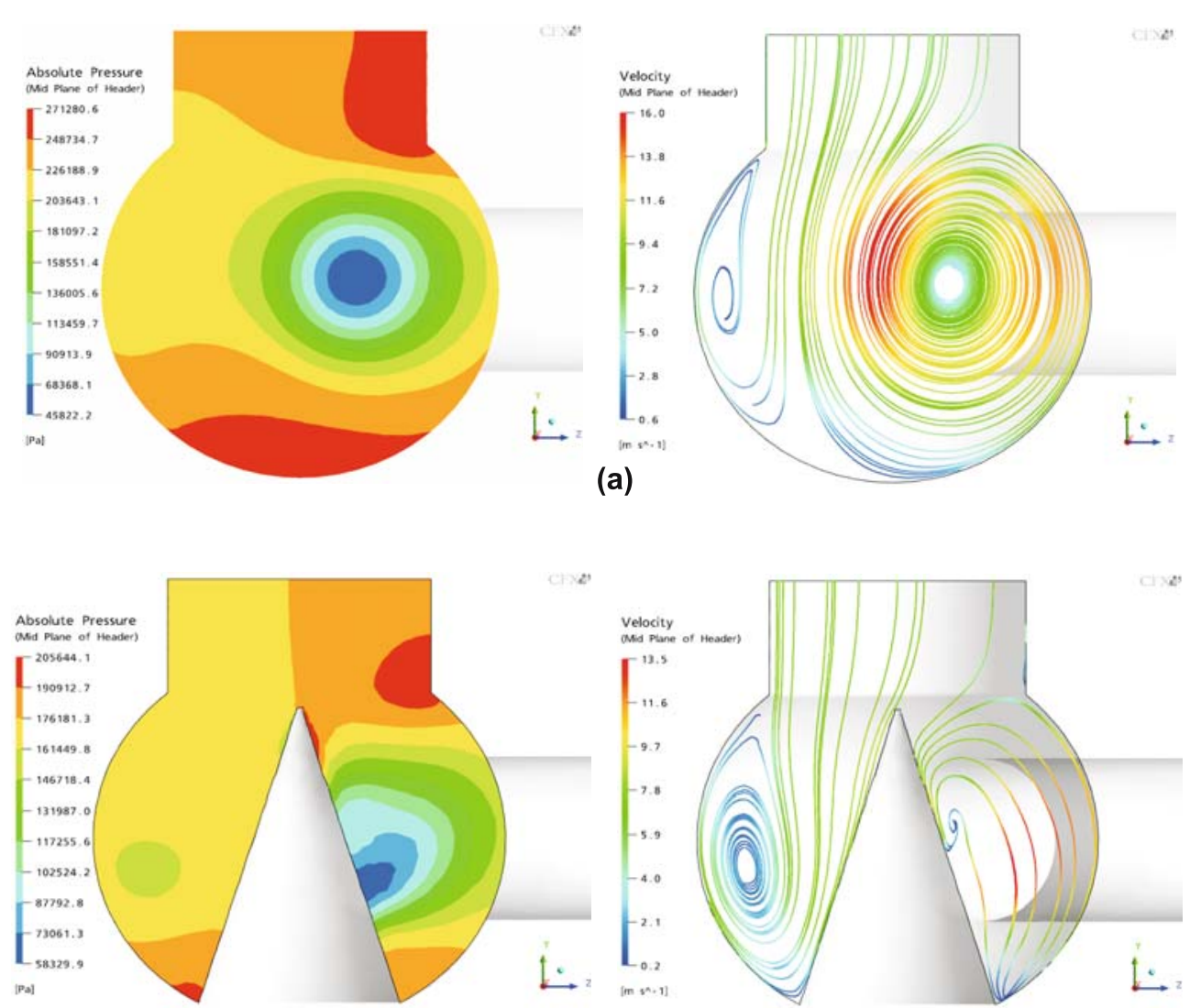

(b)
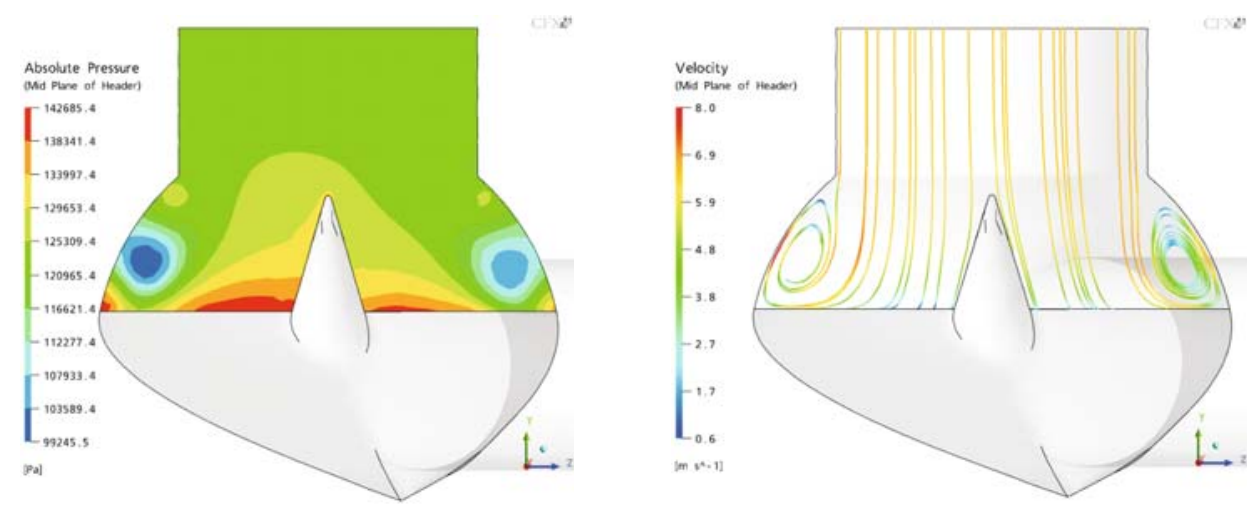

(c)

Figure 12. Static pressure distribution and stream line pattern inside the header for three configurations: (a) blank header, (b) header with a central cone and (c) header with optimized baffle. 


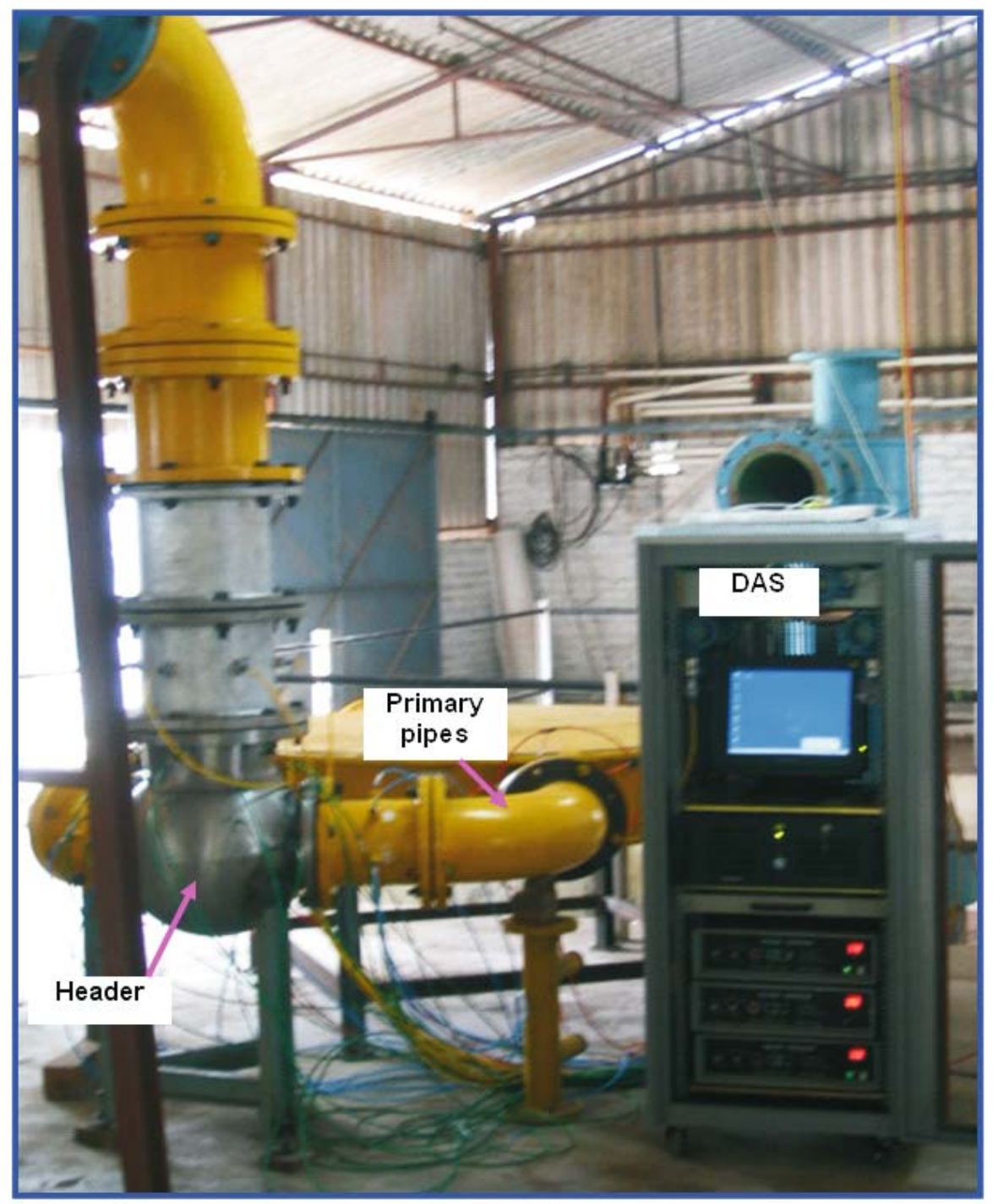

Figure 13. Experimental set-up to measure pressure loss in spherical header.

subjected to sodium cross flow velocity and to assess their risk of flow-induced vibration, detailed knowledge of velocity distribution is essential. These are predicted by 2 and 3-D CFD studies, using the PHOENICS code (version 3.5) employing a porous body model. As per this model, fine-scale structures, viz. sleeves, are not explicitly modelled in CFD mesh. However, their effects, viz. resistance to flow and enhancement in local velocity values, are accounted by (1) adding additional resistance terms in momentum equations and (2) defining surface/volumetric porosities for the control volumes. Flow distribution inside grid plate is found to be circumferentially uniform due to the presence of shielding SA sleeves. The maximum cross flow velocity seen by the sleeves is determined to be $9 \mathrm{~m} / \mathrm{s}$ while the pressure difference between the periphery and centre of grid plate is $4.6 \mathrm{mlc}$. 

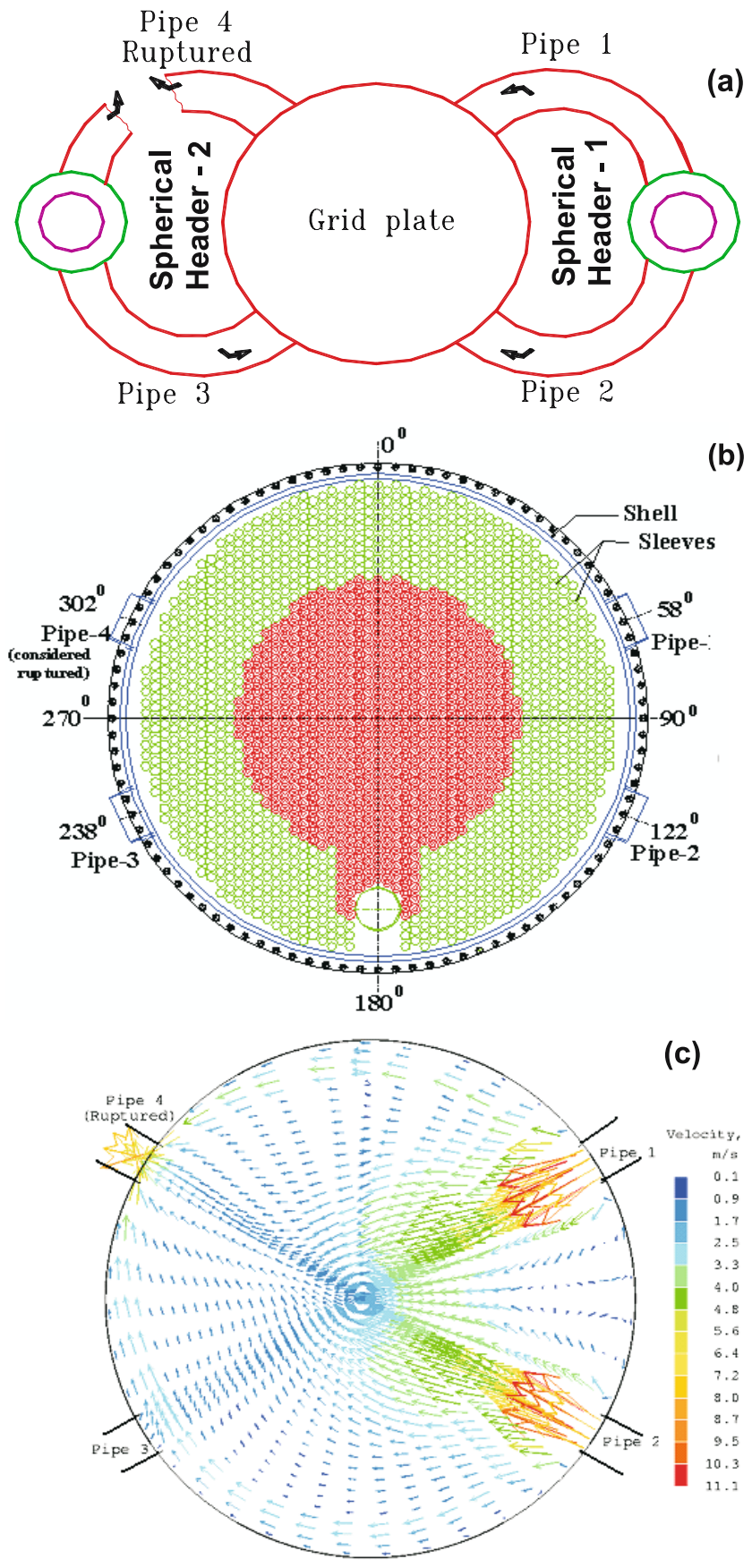

Figure 14. Internal details of grid plate and flow distribution under pipe rupture condition: (a) schematic showing pipe rupture, (b) grid plate with 1758 sleeves and (c) predicted sodium velocity.

For an unlikely accidental condition of rupture in one of the feeding pipes (figure 14), sodium bypasses the core. Adequacy of core cooling and safe shutdown of the reactor, have to be ensured under this condition. One of the critical parameters required to ensure this is core flow under pipe rupture. To determine this, 3-D CFD studies of grid plate, simulating 
sodium feeding through three primary pipes and exiting through one primary pipe as well as core SA, have been carried out. Based on these studies, it has been estimated that $33 \%$ of the flow will pass through core while the rest will flow back to cold pool through the ruptured pipe (Natesan et al 2006). Subsequent safety investigations with this core flow revealed that the temperature of fuel clad is within permissible limits, indicating that the safety of the reactor is not impaired even if a pipe rupture takes place. Predicted results of nominal pressure distribution and core flow under pipe rupture condition were found to match very well against experiments conducted on a $1 / 3$ scale air model.

\subsection{Inter-wrapper flow in decay heat removal}

Success of decay heat removal depends on deployment of final heat sink (atmospheric air) and healthiness of heat transport path from heat source to heat sink. The heat transport path is very complex, which includes two sodium pools between the heat source and the decay heat exchangers (DHX) and a sodium loop between DHX and air heat exchangers. All the sub-assemblies that constitute the core are supported over grid plate. Their bottom end is open to the common grid plate plenum and their top end is open to hot pool. A part of cold primary sodium leaving DHX rises up in the inter-wrapper space (see inset of figure 15). To study the interaction of inter-wrapper flow with hot pool sodium having vast difference in their geometric scales, a porous body approach has to be adopted. One of the inputs for the porous body formulation is knowledge of pressure drop and heat transfer coefficient for inter-wrapper flow. These pressure drop and heat transfer correlations have been developed by detailed 2-D CFD studies, using STAR-CD code (version 3.15). The predicted pressure loss coefficient as a function of Reynolds number is depicted in figure 15.

Towards assessing the temperature evolution in critical structures of hot and cold pools and clad of the fuel and storage sub-assemblies, multi-dimensional CFD analyses using STAR-CD

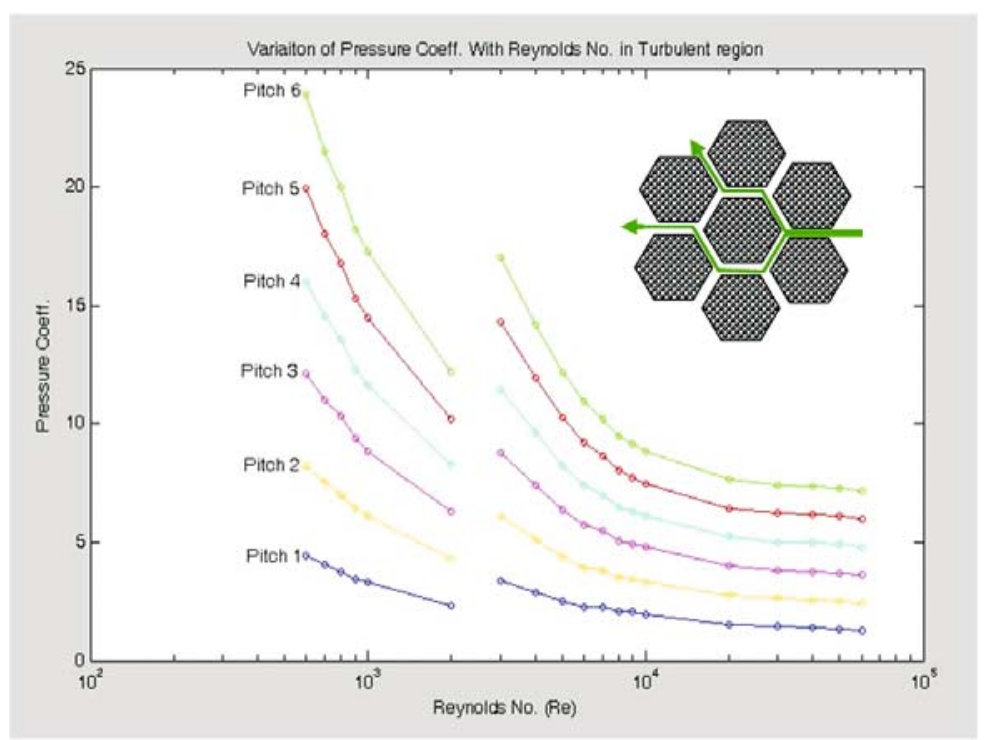

Figure 15. CFD prediction of pressure loss coefficient for inter-wrapper flow as a function of number of rows crossed and Reynolds number. 

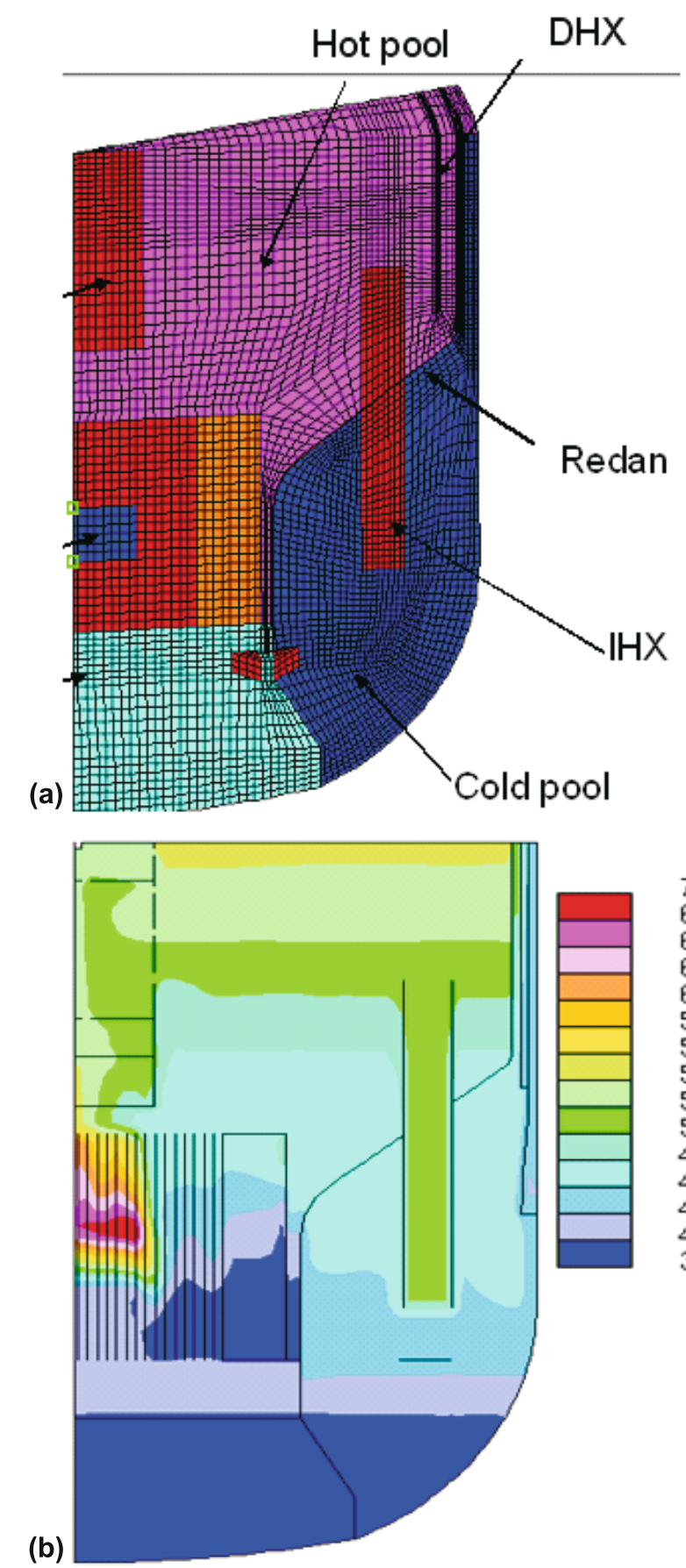

706.0

683.9

661.8

639.7

617.6

595.5

573.3

551.2

529.1

507.0

484.9

462.8

440.7

418.5

396.4

(b) 
code (version 3.15) coupled with 1-D system models for intermediate sodium loop, air heat exchanger and stack, have been carried out. The predicted temperature evolution in hot and cold pools at a particular instant is depicted in figure 16 along with the finite volume mesh. Further, the heat removal capability of inter-wrapper flow has been established and it is found that the temperature limits of core and pool are satisfactorily met under natural convection condition.

\subsection{Investigations of flow reversal in decay heat exchangers}

One design of DHX has ' $U$ ' tubes with two-passes. There are 90 tubes which are arranged to have 5 inner rows and 2 outer rows and are supported by anti-vibration plates along the length. Intermediate sodium enters the inner rows of tubes from top, picks up heat from primary sodium and leaves from outer rows at the top. Primary sodium from hot pool enters DHX in radial direction through a perforated outer shell, exchanges heat with intermediate sodium, gets cooled and leaves back to the pool through bottom window. To enable connectivity between the 5 inner rows and 2 outer rows through $U$ bends, the lengths of $U$-tubes are made unequal. Also, the tubes see varying primary sodium temperature. Due to these reasons, there is a risk of flow reversal in some tubes. Flow reversal adversely affects the heat removal capacity of Safety Grade Decay Heat Removal System (SGDHRS) and hence, it is essential to investigate the possibility of flow reversal in tubes. The flow and temperature distributions of intermediate sodium in tubes and primary sodium on shell side have been solved as a conjugate problem, using STAR-CD code (version 3.15). THYC-3D code could not be used as this code solves the governing equations only in regular coordinate system, while the present problem requires a body fitted coordinate system. The intermediate sodium temperature distribution along the length of tube centreline for all the 15 tubes, which form a symmetric sector, is shown in figure 17a. The minimum and maximum values of intermediate sodium flow rates in the tube were seen to be $0.31 \mathrm{~kg} / \mathrm{s}$ and $0.38 \mathrm{~kg} / \mathrm{s}$ respectively against the mean value of $0.36 \mathrm{~kg} / \mathrm{s}$, as depicted in figure $17 \mathrm{~b}$. In general, flow rate is higher in the outermost row which is connected to three inner rows. That is, the flow rate is more in the tubes where heat transfer is more in the upward leg. The differences in the flow rates among the tubes are only marginal and there is no risk of flow reversal in the tubes. More details about this study can be had from (Rajendrakumar et al 2007).

\subsection{Cover gas thermal hydraulics}

As already mentioned, argon cover gas is maintained above the sodium-free level to accommodate (i) volume changes in sodium due to various operating states/transients, (ii) to avoid sodium-air contact and (iii) to reduce heat load to topshield. The topshield is filled with concrete for the purpose of shielding and the temperature of concrete cannot exceed $120^{\circ} \mathrm{C}$ (figure 18a). Hence, the topshield is air-cooled. The primary sodium temperature in hot pool is $547^{\circ} \mathrm{C}$ during normal operating condition. As a result of these temperature conditions, natural convection of argon takes place, which transports sodium vapour from free level and deposits in colder regions of topshield. Solidification of sodium vapour in colder regions offers difficulties in free movement of the components. Also, heat is transferred to topshield by thermal radiation.

The topshield has many narrow enclosures opened at the bottom due to component penetrations. The annular gap widths of the enclosures have to be minimum to resist natural convection so that the heat load to roof slab cooling system is low. Narrower gap widths are also preferred to have compact layout and smaller size of roof slab. From the points of view of 

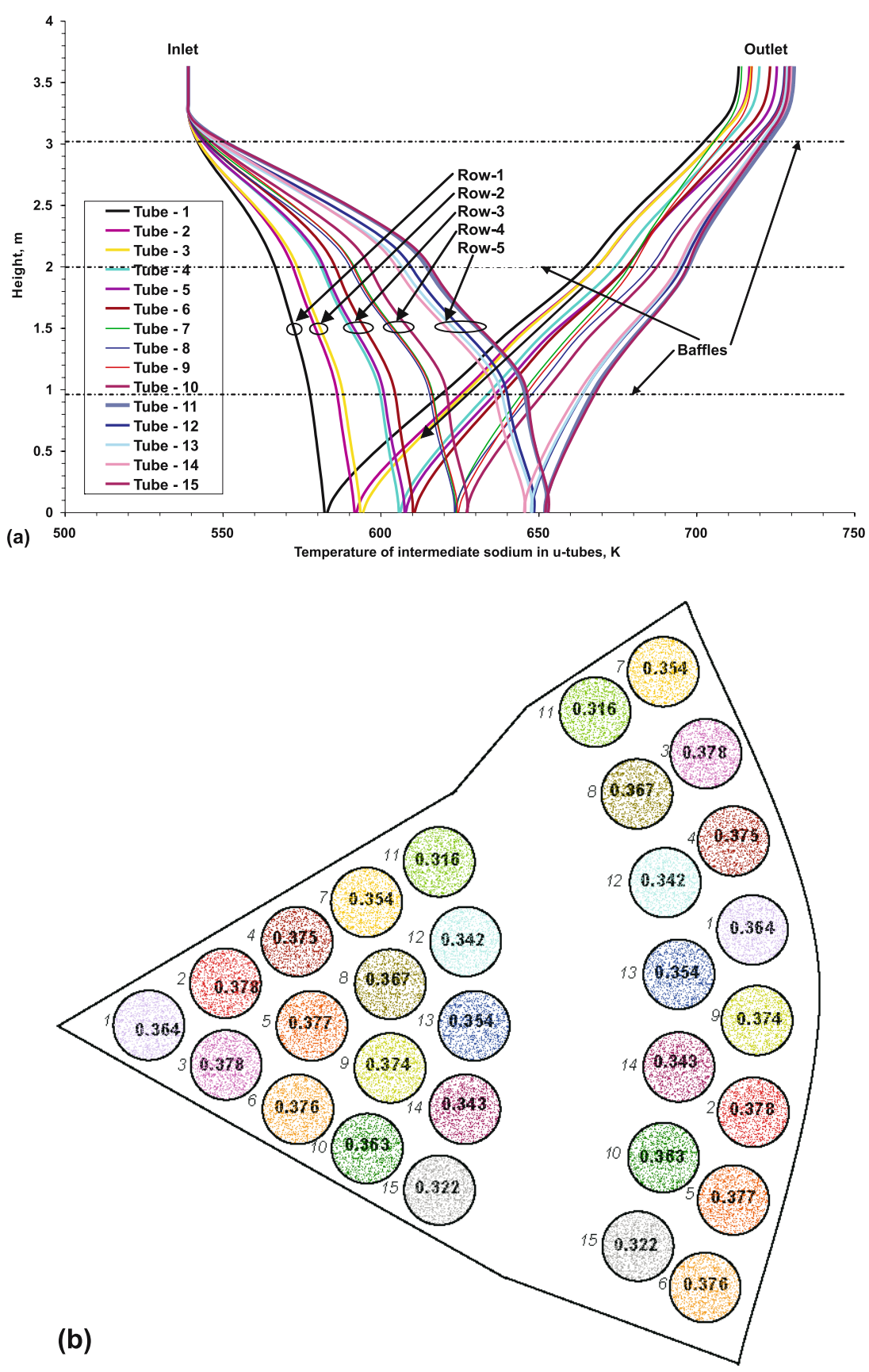

Figure 17. (a) Central line temperature of intermediate sodium inside U-tubes. (b) Mass flow rate $(\mathrm{kg} / \mathrm{s})$ of intermediate sodium in U-tubes. 
(a)
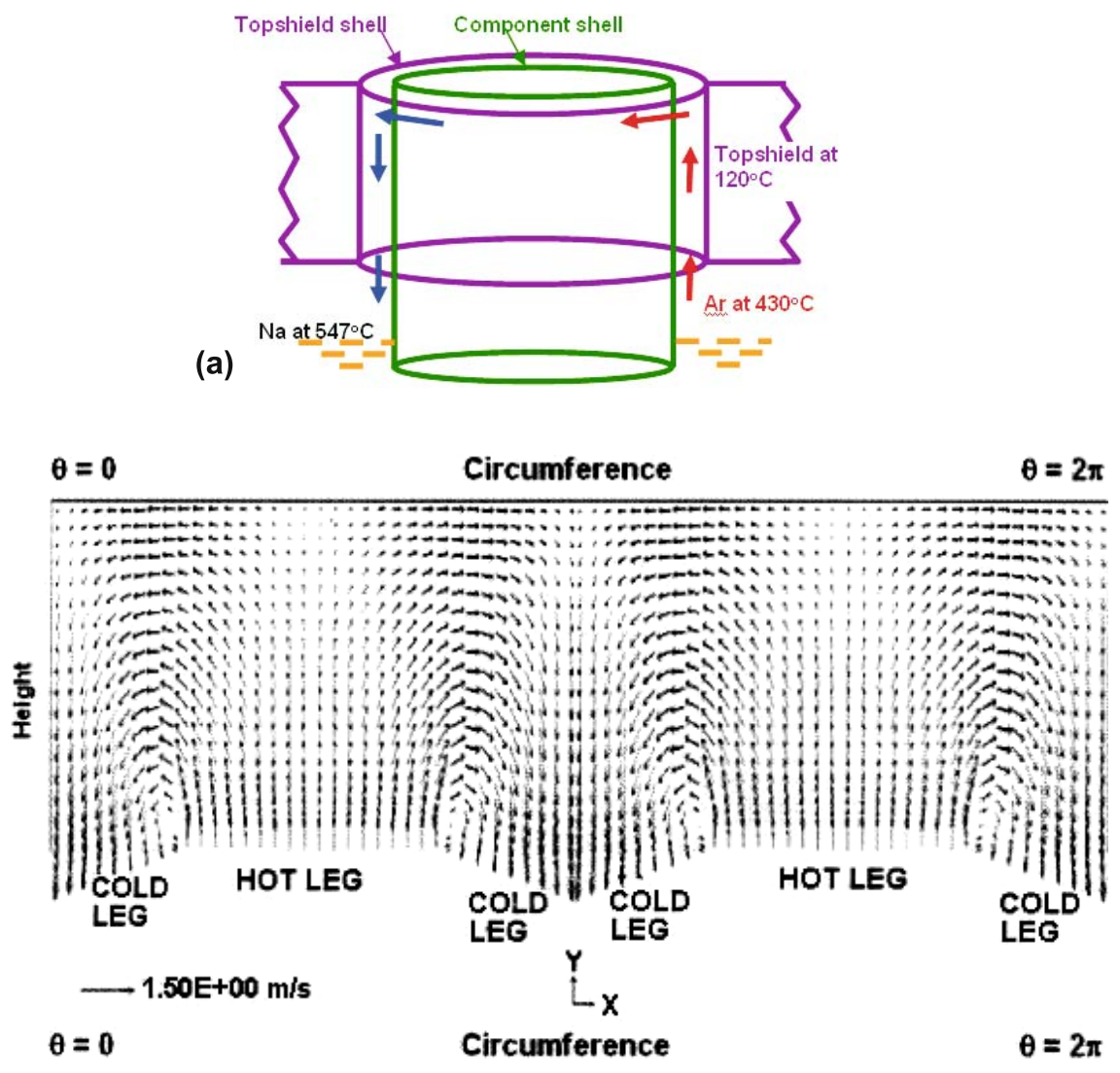

(b)

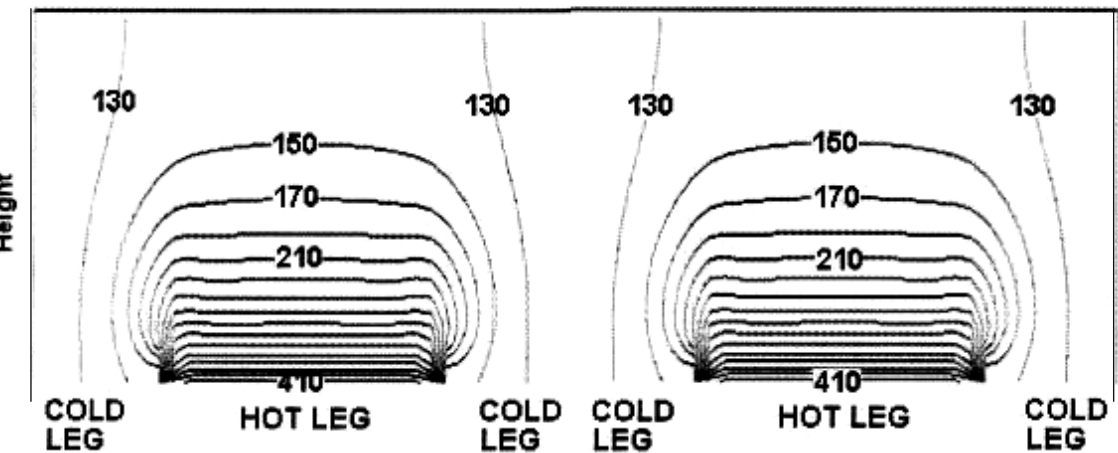

Figure 18. (a) Cellular convection of argon. (b) Natural convective velocity of argon (top) and its temperature $\left({ }^{\circ} \mathrm{C}\right)$ (bottom) in rotating plug penetration.

easier insertion/removal of components and to accommodate manufacturing tolerances, finite sizes of gaps have to be provided. Typical gap width is of the order of $15-30 \mathrm{~mm}$ whereas the enclosure height is about $1.8 \mathrm{~m}$. Because of the large aspect ratio of the enclosure $(\sim 100)$, the resulting natural convection is not axi-symmetric and is asymmetric (figure 18a). This leads to circumferential non-uniformity in temperature of enclosure walls. This non uniformity of temperature leads to uneven vertical expansion and stress. Apart from natural convective heat 
exchange between the fluid and the walls, the walls interact via surface radiation. Also the walls are thick enough to conduct heat in vertical and circumferential directions. Analysis of these phenomena is essential to estimate temperature distribution in the walls, to estimate the cooling load and to decide upon cooling arrangement. Based on CFD analyses considering natural convection of argon, 3-D heat conduction in shells, forced cooling of air and surface radiation interaction among shells simultaneously, the temperature distributions in the shells of topshield and heat load on the cooling system have been determined to have a sound thermal design of the topshield. For this purpose, THYC-2D code has been utilised along with user codes for shell/air temperature distributions. The THYC-2D predicted argon velocity and temperature distributions for the rotating plug penetration are depicted in figure $18 \mathrm{~b}$.

\subsection{Investigations of gas entrainment}

The free surfaces of sodium pools are not static and are associated with significant vertical and horizontal velocities. These velocities lead to free level fluctuations and formation of vortices, which are potential sources for gas entrainment in sodium pools. Mechanisms of gas entrainment, transportation of gas to grid plate through IHX, agglomeration of gas inside grid plate and its final passage through core (figure 19a) have to be understood well. This is an important safety problem as passage of argon gas through core leads to positive reactivity.

The velocity distribution predicted in hot pool is depicted in figure 19b. It is seen that core flow enters hot pool as a horizontal jet in between the control plug skirt and sub-assembly top. It induces a large anti-clockwise circulation zone, which occupies almost the entire hot pool. The maximum horizontal velocity with which the jet enters hot pool is $\sim 3 \mathrm{~m} / \mathrm{s}$ and as a result of this, the maximum horizontal velocity on free surface is seen to be $\sim 1.0 \mathrm{~m} / \mathrm{s}$ (figure 19c). The reason for this high free surface velocity is the presence of skirt. To avoid gas entrainment, the free surface velocity of sodium has to be less than $0.5 \mathrm{~m} / \mathrm{s}$. Reduction of free surface velocity is possible by altering hot pool flow pattern such that the influence of core jet is minimized near the free surface.

Detailed 3-D thermal hydraulic studies have been carried out using the PHOENICS code (version 3.5), to see the efficacy of using baffles in reducing free level velocity. This code is adopted due to its validation against hot pool water model tests (section 5.1). In this study, plates were considered inside hot pool at various possible locations, considering (a) interference with fuel handling mechanism, (b) smooth sodium flow to decay heat exchangers under natural convection conditions, and (c) structural stability of the plates. The plate shape, size and its location have been varied as parameters to determine the flow distribution in hot pool. It is seen that by having a horizontal baffle of $0.5 \mathrm{~m}$ width attached to 'upper shell' of inner vessel and lowering the roof slab inner shell up to IHX inlet, the free surface velocity could be reduced to $0.40 \mathrm{~m} / \mathrm{s}$ (figure $19 \mathrm{~d}$ ).

Another source of gas entrainment is the over-flow weir of main vessel cooling system. Unfortunately, free surface flows are not readily amenable for CFD simulation. Hence, detailed experimental investigations have been carried out on a spillway weir crest in main vessel cooling circuit, to assess flow separation, gas entrainment and liquid film thickness over spillway weir. The full scale slab model is based on Froude similarity, wherein the fall height and water flow rate have been varied as parameters. Variation of liquid film thickness over the outer thermal baffle has been measured by a special conductance cum position sensor (figure 20). Measured film thickness and the subsequent numerical integration of the governing equations suggest that there is no flow separation in the chosen profile of weir-crest. It is found that gas bubbles entrain in the collector plenum for all fall heights greater than $\sim 100 \mathrm{~mm}$ irrespective of the flow rate. However, all the entrained air bubbles bubble out to free surface. 


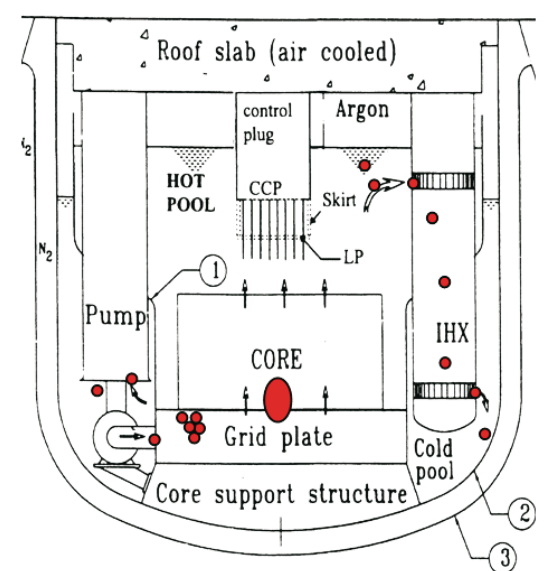

(a)

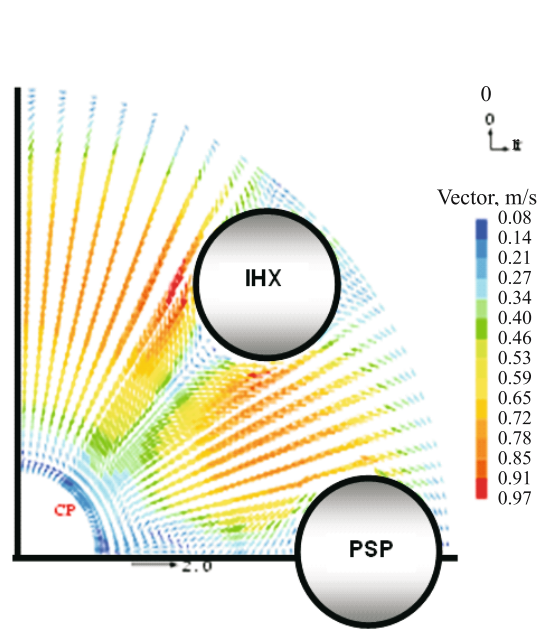

(c)

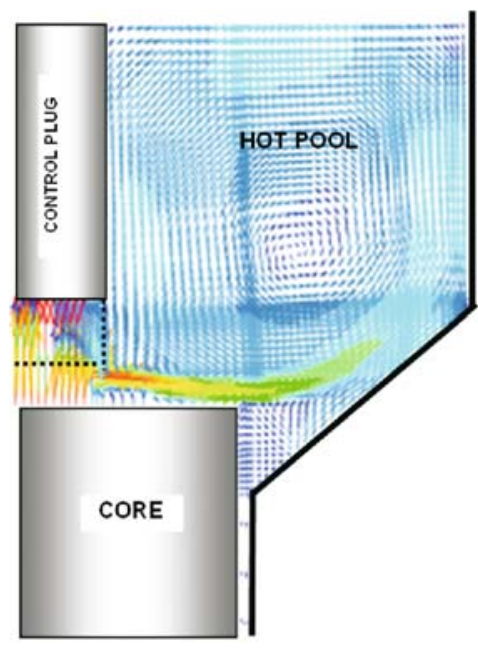

(b)

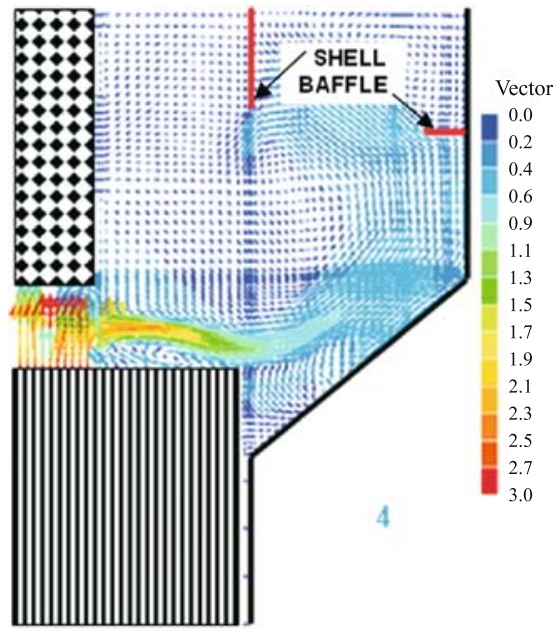

(d)

Figure 19. Free surface velocity $(\mathrm{m} / \mathrm{s})$ reduced to acceptable level by introduction of baffles: (a) gas transport path, (b) reference case velocity in a vertical plane, (c) reference case free surface velocity and (d) free surface velocity reduced by the introduction of baffles.

They penetrate to a maximum depth of only $700 \mathrm{~mm}$. This depth is only about $1 / 4$ the depth of sodium available in the collector plenum and hence, it is established that there is no fear of gas entrainment in main vessel cooling system.

\subsection{Sodium leakage through bolted joints in grid plate}

Grid plate (GP), which supports core, consists of perforated top and bottom plates bolted to a flanged intermediate shell. These plates are also connected by sleeves having circular nuts. Due to high pressure (6.2 bar-g) inside the GP, sodium leaks through these joints. As this 

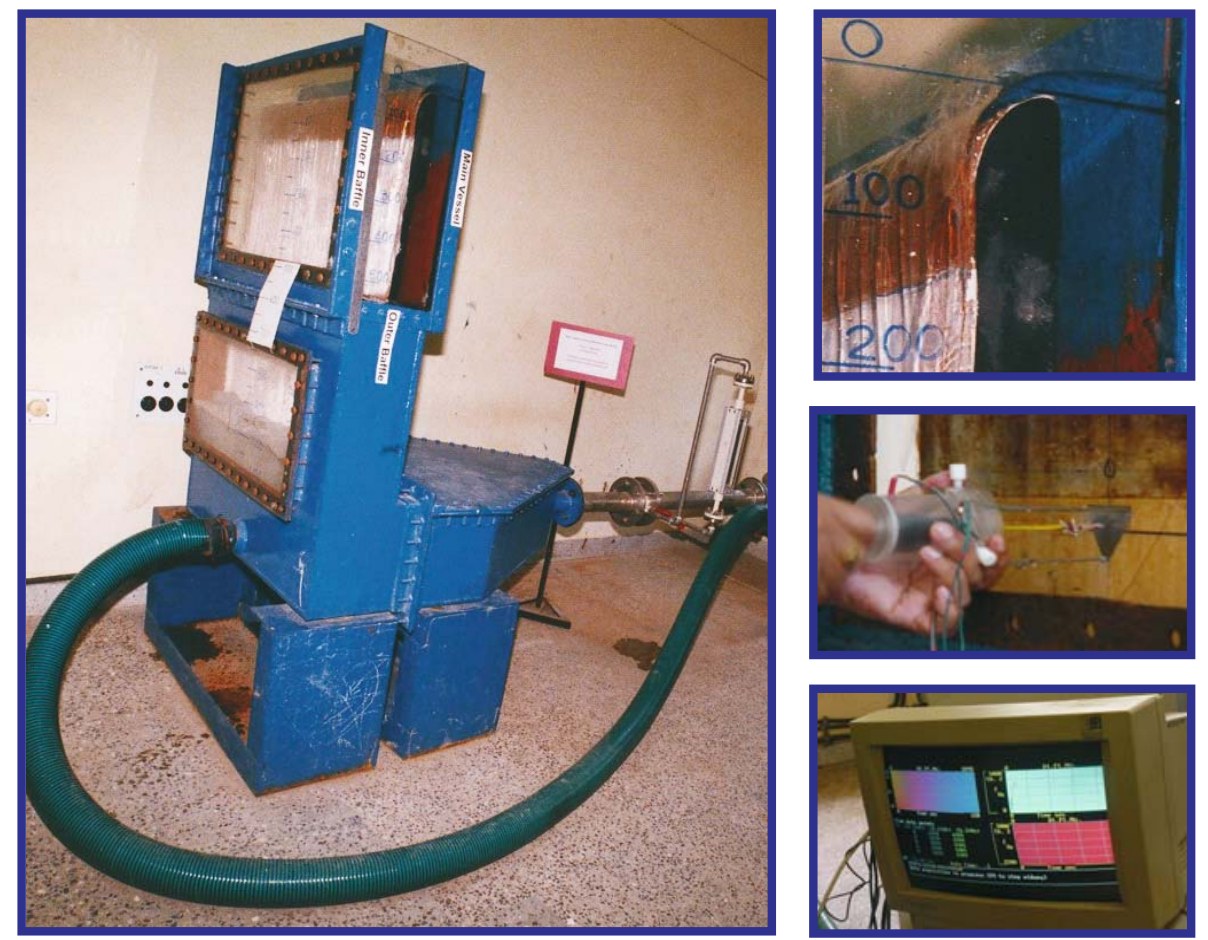

Figure 20. Weir-Crest testing full scale water model (left) and water film thickness being measured (right) by a special conductance probe connected to data acquisition system.

leak bypasses the core, it is essential that this leak be minimal. Knowledge of sodium leak through the joints is essential to decide the tightening torque for the sleeves and flange nuts and to assess the adequacy of core flow. This problem is also not amenable for numerical simulations. Hence, a model grid plate developed as a part of technology development has been judiciously utilized for experimental prediction of sodium leak. Experiments have been conducted in water at various pressures and for various values of tightening torque. Leak rates through 19 representative sleeves and flanges have been measured using laser level sensors (figure 21). Using appropriate scaling laws, the leak rate for reactor has been extrapolated. Based on the tests, it is established that (i) the total sodium leak in reactor is $3.4 \mathrm{~kg} / \mathrm{s}$, which is $\sim 0.05 \%$ of core flow and (ii) the required bolt tightening torque is $350 \mathrm{~N}-\mathrm{m}$, which are acceptable. Also, the tolerance specified and achieved in manufacturing of GP are very well acceptable.

\section{Summary}

Characteristics of liquid metal pool hydraulics in a fast breeder reactor have been described. Multi-dimensional, multi-scale and multi-physics heat transfer studies with reference to a successful design of Indian Prototype Fast Breeder Reactor have been elaborated. The important role played by CFD in performing challenging thermal hydraulic analyses and identifying design solutions for critical issues are highlighted. Experiments performed to 


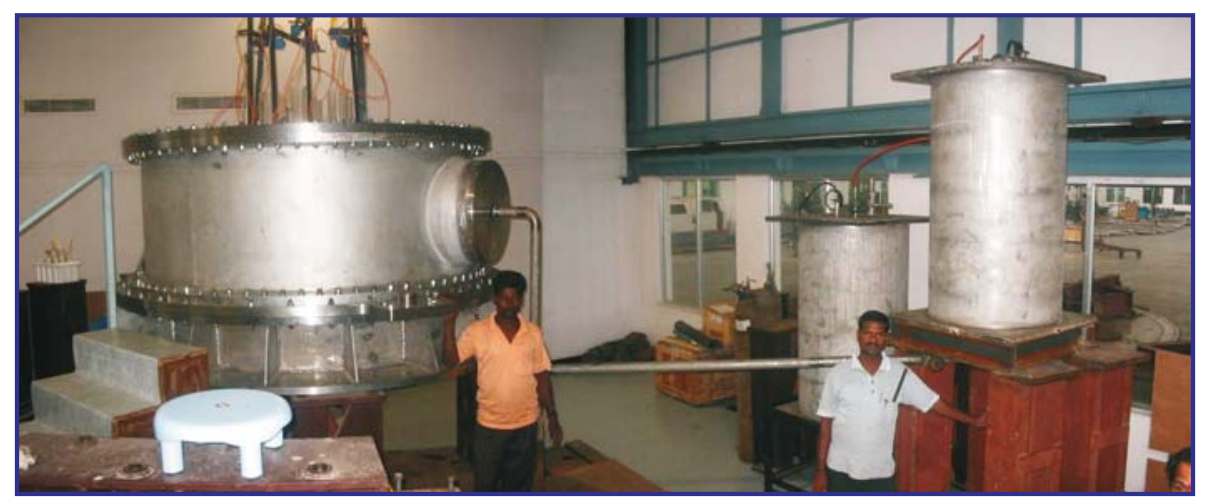

(a)

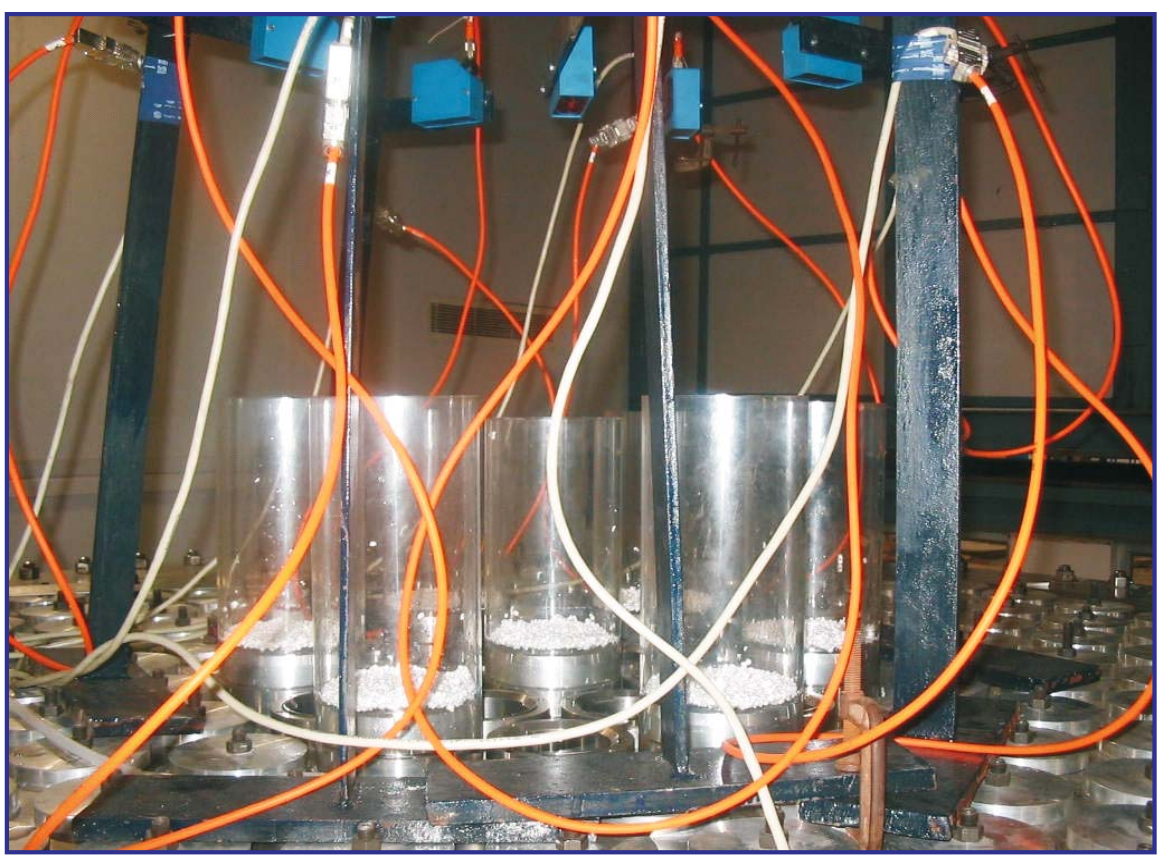

(b)

Figure 21. Experimental facility for leak tests: (a) grid plate with full scale features and pressurization circuit and (b) laser level sensors with perspex jars for leak rate measurement.

validate the design arrived at through CFD investigations and to simulate special phenomena which are not amenable for CFD studies have also been discussed. It may be highlighted that appropriate factors of safety have been considered while using these data in the design of reactor components, commensurate with the reliability requirements of the components. Further, many of the phenomena discussed in this paper will be verified during initial commissioning of the reactor either directly or indirectly. 
Some of the numerical calculations have been carried out by the engineers of Thermal Hydraulics Section, while the experiments have been carried out in the Structural Mechanics Laboratory, Indira Gandhi Centre for Atomic Research, Kalpakkam. The analysis and experimental supports from our collaborators, viz. Indian Institute of Technology (IIT) Madras, Anna University, Chennai and Fluid Control Research Institute, Palghat are gratefully acknowledged.

\section{References}

Asok Kumar M 1990 THYC-3D, A computer code for thermal hydraulic analysis. Proc. $4^{\text {th }}$ Int. Conf. on Simulation Methods in Nuclear Engineering, Montreal

Azarian M, Astegiano J C, Tenchine D, Lacroix M, Vidard M 1990 Sodium thermal-hydraulics in the pool LMFBR primary vessel. Nuclear Eng. and Design 124: 417-430

CFX (http://www.ansys.com/products/fluid-dynamics/cfx).

Chetal S C, Bhoje S B, Kale R D, Rao A S L K, Mitra T K, Selvaraj A, Sethi V K, Sundaramoorthy T R, Balasubramaniyan V, Vaidyanathan G 1995 Conceptual design of heat transport system and components of PFBR - NSSS. Proc. of IAEA Tech. Committee Meeting. Conceptual Design of Advanced Fast Reactors, IAEA-TECDOC-907, Kalpakkam, India, 11-132

FLUENT (http://www.fluent.com).

Francois G, Azarian G, Astegiano J C, Lacroix C, Poet G 1990 Assessment of thermal-hydraulic characteristics of primary circuit, Nuclear Sci. and Eng. 106: 55-63

Gajapathy R, Velusamy K, Selvaraj P, Chellapandi P, Chetal S C 2007 CFD investigation of helical wire-wrapped 7-pin fuel bundle and the challenges in modeling full scale 217 pin bundle, Nuclear Eng. and Design 237(24): 2332-2342

Gelineau O, Sperandio M 1994 Thermal fluctuation problems encountered in LMFBRs, Proc. IAEAIWGFR/90, Specialistic meeting on correlation between material properties and thermohydraulics conditions in LMFBRs, Aix-en-Provence, France 22-24

Hughes W F, Gaylord E W 1964 Basic equations of engineering science (NY: McGraw-Hill)

Kamzaki Y, Takeishi M, Ueda S, Fujimoto T 1995 Heat transfer studies on a reactor vessel cooling system. Proc. $3^{\text {rd }}$ Int. Conf. Nuclear Engineering, Japan 35-40

Launder B E, Spalding D B 1974 The numerical computation of turbulent flow. Computer methods in applied mechanics and engineering 13: 269-289

Mochizuki H 2007 Inter-subassembly heat transfer of sodium cooled fast reactors: Validation of the NETFLOW code. Nuclear Eng. and Design 237(19): 2040-2053

Natesan K, Kasinathan N, Velusamy K, Selvaraj P, Chellapandi P, Chetal S C 2006 Thermal hydraulic investigations of primary coolant pipe rupture in an LMFBR. Nuclear Eng. and Design 236(11): $1165-1178$

Nishimura M, Kamide H, Hayashi K, Momoi K 2000 Transient experiments on fast reactor core thermal-hydraulics and its numerical analysis - Inter-subassembly heat transfer. Nuclear Eng. and Design 200(1): 157-175

Patankar S V 1980 Numerical heat transfer and fluid flow, Hemisphere

PHOENICS (http://www.cham.co.uk).

Rajakumar A, Velusamy K, Vaidyanathan G 1987 Thermo-hydraulic analysis of LMFBR plenum. Proc. $9^{\text {th }}$ Natl. Heat and Mass Transfer Conf., IISc. Bangalore, HMT-30-87

Rajendrakumar M, Velusamy K, Selvaraj P, Chellapandi P 2007 Coupled CFD investigation of flow and temperature distributions in buoyancy driven decay heat exchangers of indian fast breeder reactor. Proc. $7^{\text {th }}$ Asian CFD Conf., Indian Institute of Science, Bangalore 26-30

STAR-CD (http://www.cd-adapco.com/products/STAR-CD). 
Tokuhiro A, Kimura N 1999 An experimental investigation on thermal stripping mixing phenomena of a vertical non-buoyant jet with two adjacent buoyant jets as measured by ultrasound doppler velocimetry. Nuclear Eng. and Design 188: 49-73

Velusamy K, Sundararajan T, Vaidyanathan G, Chetal S C, Bhoje S B 1997 Mixed convection in main vessel cooling circuit of PFBR, Proc. $3^{\text {rd }}$ ISHMT-ASME Heat and Mass Transfer Conf., I.I.TKanpur Sept. 29-31: 1011-1016

Velusamy K, Vaidyanathan G, Sundararajan T, Chetal S C, Bhoje S B 1998 Natural convection in narrow component penetrations of PFBR Roof Slab. Heat and Mass Transfer 20: 1-11

Velusamy K, Raghunath Babu D V V, Chellapandi P, Gangoli S S R 2002 Three dimensional thermal hydraulic analysis of main vessel cooling circuit of an LMFBR using boundary fitted mesh. Proc. $5^{\text {th }}$ ISHMT-ASME Heat and Mass Transfer Conference Jan. 3-5, 1285-1290

Velusamy K, Sundararajan T, Chellapandi P, Selvaraj P, Chetal S C 2005 Investigations of thermal stripping in primary circuit of prototype fast breeder reactor. Proc. $13^{\text {th }}$ Int. Conf. Nulear Eng., Beijing, China, May 16-20

Velusamy K, Selvaraj P, Chellapandi P, Chetal S C, Sudhakar P, Jebaraj C, Mascomani R 2007 Computational prediction and experimental validation of pressure drop in the spherical header of PFBR sodium pump $15^{\text {th }}$. Int. Conf. Nuclear Eng. Nagoya, Japan, April 22-26

Wakamatsu M, Nei H, Hashiguchi K 1995 Attenuation of temperature fluctuations in thermal stripping. Nuclear Sci. and Technol. 32(8): 752-762 